\title{
A 6-year global cloud climatology from the Atmospheric InfraRed Sounder AIRS and a statistical analysis in synergy with CALIPSO and CloudSat
}

\author{
C. J. Stubenrauch, S. Cros, A. Guignard, and N. Lamquin \\ Laboratoire de Météorologie Dynamique, IPSL/CNRS, UMR 8539, Ecole Polytechnique, France
}

Received: 15 February 2010 - Published in Atmos. Chem. Phys. Discuss.: 30 March 2010

Revised: 11 July 2010 - Accepted: 30 July 2010 - Published: 6 August 2010

\begin{abstract}
We present a six-year global climatology of cloud properties, obtained from observations of the Atmospheric Infrared Sounder (AIRS) onboard the NASA Aqua satellite. Cloud-Aerosol Lidar and Infrared Pathfinder Satellite Observations (CALIPSO) combined with CloudSat observations, both missions launched as part of the A-Train in 2006, provide a unique opportunity to evaluate the retrieved AIRS cloud properties such as cloud amount and height. In addition, they permit to explore the vertical structure of different cloud types. AIRS-LMD cloud detection agrees with CALIPSO about $85 \%$ over ocean and about $75 \%$ over land. Global cloud amount has been estimated from $66 \%$ to $74 \%$, depending on the weighting of not cloudy AIRS footprints by partial cloud cover from 0 to 0.3 . $42 \%$ of all clouds are high clouds, and about $42 \%$ of all clouds are single layer low-level clouds. The "radiative" cloud height determined by the AIRS-LMD retrieval corresponds well to the height of the maximum backscatter signal and of the "apparent middle" of the cloud. Whereas the real cloud thickness of high opaque clouds often fills the whole troposphere, their "apparent" cloud thickness (at which optical depth reaches about 5) is on average only $2.5 \mathrm{~km}$. The real geometrical thickness of optically thin cirrus as identified by AIRS-LMD is identical to the "apparent" cloud thickness with an average of about $2.5 \mathrm{~km}$ in the tropics and midlatitudes. High clouds in the tropics have slightly more diffusive cloud tops than at higher latitudes. In general, the depth of the maximum backscatter signal increases nearly linearly with increasing "apparent" cloud thickness. For the same "apparent" cloud thickness
\end{abstract}

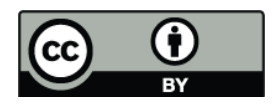

Correspondence to: C. J. Stubenrauch (stubenrauch@1md.polytechnique.fr) optically thin cirrus show a maximum backscatter about $10 \%$ deeper inside the cloud than optically thicker clouds. We also show that only the geometrically thickest opaque clouds and (the probably surrounding anvil) cirrus penetrate the stratosphere in the tropics.

\section{Introduction}

Clouds cover more than two thirds of the Earth's surface, and hence they play a dominant role in the energy and water cycle of our planet. Satellite observations offer a unique possibility to survey cloud properties on a global and continuous scale, and their record length exceeds now more than 25 years. Within the framework of the World Climate Research Programme (WCRP), the Radiation panel of the Global Energy and Water Experiment (GEWEX) has initiated a cloud assessment to evaluate the quality of climate records of cloud properties, with special emphasis on the GEWEX cloud products from the International Satellite Cloud Climatology Project (ISCCP, Rossow and Schiffer, 1999). To resolve the diurnal cycle of clouds, ISCCP uses VIS (day only) and IR atmospheric window radiance measurements from imagers on geostationary and polar orbiting weather satellites. Time sampling is three hourly, and the initial spatial resolution of about $7 \mathrm{~km}$ is sampled at about $30 \mathrm{~km}$. Cloud detection is based on space and time variability of the IR and VIS radiances. First intercomparisons of about ten different cloud climatologies have highlighted the different sensitivities of various instruments and retrieval methods (Stubenrauch et al., 2009). Compared to other passive remote sensing instruments, the high spectral resolution of IR vertical sounders leads to especially reliable properties of cirrus with optical

Published by Copernicus Publications on behalf of the European Geosciences Union. 
depth as low as 0.1, day and night (e.g. Wylie et al., 1994; Ackerman et al., 1995; Smith et al., 1998; Stubenrauch et al., 1999b, 2006; Wylie and Menzel, 1999; Chung et al., 2000; Kahn et al., 2007).

$\mathrm{CO}_{2}$ sensitive channels of IR vertical sounders allow the determination of cloud height and cloud emissivity of a single cloud layer (the uppermost cloud layer in the case of multi-layer cloud scenes). Radiances measured from near the centre of $\mathrm{a} \mathrm{CO}_{2}$ absorption band are only sensitive to the upper atmosphere while radiances from the wings of the band (away from the band centre) successively probe lower levels of the atmosphere. The TIROS-N Operational Vertical Sounders onboard the NOAA polar satellites provide data since 1979, the Atmospheric InfraRed Sounder (AIRS) onboard Aqua since 2002 and the IR Atmospheric Sounding Interferometer (IASI) onboard METOP since 2006. The ATrain mission (Stephens et al., 2002), consisting of several passive and two active remote sensing instruments in constellation with the Aqua satellite, provides a unique possibility to explore the geometrical depth and multi-layer structure of clouds. The Cloud-Aerosol Lidar with Orthogonal Polarization (CALIOP) of the Cloud-Aerosol Lidar and Infrared Pathfinder Satellite Observations (CALIPSO) mission (Winker et al., 2007, 2009) is also sensitive to very thin cirrus (such as subvisible cirrus with optical depth down to 0.01) and provides information on multiple cloud layers as long as clouds are optically not too thick. In the latter case, the cloud profiling radar (CPR) of the CloudSat mission (Stephens et al., 2002; Mace et al., 2007) helps to complete the information on vertical cloud layer structure. For this purpose, the Cloudsat Geometrical Profiling Product (GEOPROF; Mace et al., 2007; Marchand et al., 2008) and the CALIPSO Vertical Feature Mask (VFM, Vaughan et al., 2004) have been merged into a combined Radar-Lidar Geometrical Profile Product (Radar - Lidar GEOPROF; Mace et al., 2009).

In this article we present cloud properties, retrieved from AIRS data by a weighted $\chi^{2}$ method (Stubenrauch et al., 1999a). The AIRS-LMD cloud property retrieval, first developed for tropical and subtropical latitude bands $\left(30^{\circ} \mathrm{N}\right.$ to $30^{\circ} \mathrm{S}$ ) and presented in (Stubenrauch et al., 2008), has been refined and extended to the whole globe. The retrieval is applied to all data, after which a test based on the spectral coherence of cloud emissivities, determined at wavelengths between 9 and $12 \mu \mathrm{m}$ by using the retrieved cloud pressure, decides whether the AIRS footprint is cloudy or mostly clear. Thresholds have been established by comparing clear and cloudy scenes within the AIRS footprints, distinguished by coincident CALIOP measurements.

Section 2 describes the AIRS-LMD cloud property retrieval algorithm, which makes use of retrieved atmospheric temperature and water vapour profiles of the AIRS L2 data (Susskind et al., 2003, 2006) and of atmospheric spectral transmissivity profiles which have been simulated for atmospheric profiles of the Thermodynamic Initial Guess Retrieval (TIGR) data base (Chédin et al., 1985; Chevallier et al., 1998). AIRS data have been collocated with CALIPSO data and then with the Radar - Lidar GEOPROF data. The latter complete the information on vertical cloud layer structure, when the lidar cannot completely penetrate the whole cloud column. These data are used to choose tests to determine the AIRS cloud amount and to evaluate the AIRS cloud height. Section 3 gives an overview of average cloud properties of the 6-year AIRS-LMD cloud climatology. High clouds are studied in more detail in Sect. 4, in combination with CALIPSO and Radar - Lidar GEOPROF data. Conclusions are drawn in Sect. 5.

\section{Data and methods}

\subsection{AIRS data}

Launched in May 2002 onboard the Earth Observing System (EOS) platform Aqua, the AIRS instrument (Aumann et al., 2003; Chahine et al., 2006) provides very high spectral resolution measurements of Earth emitted radiation in three spectral bands $(3.74-4.61 \mu \mathrm{m}, 6.20-8.22 \mu \mathrm{m}$ and 8.80 $15.40 \mu \mathrm{m})$ using 2378 channels with a spectral resolution given by $\Delta \lambda \lambda=0.0008$. The polar orbiting Aqua satellite provides observations at 01:30 and 13:30 local time (LT). The spatial resolution of these measurements is $13.5 \mathrm{~km}$ at nadir. Nine AIRS measurements $(3 \times 3)$ correspond to one footprint of the Advanced Microwave Sounder Unit (AMSU), and is called a 'golf ball'. AIRS L2 standard products include temperature at 28 pressure levels from $0.1 \mathrm{hPa}$ to the surface and water vapour mixing ratios in 14 pressure layers from $50 \mathrm{hPa}$ to the surface (Susskind et al., 2003, 2006). These atmospheric profiles were retrieved from cloud-cleared AIRS radiances (Chahine et al., 2006) within each AMSU footprint. Validations with radiosonde data from the NOAA-NESDIS operational meteorological database archive (Divakarla et al., 2006) and with Atmospheric Radiation Measurement (ARM) data (Tobin et al., 2006) have shown that the accuracy is close to $1 \mathrm{~K}$ in $1 \mathrm{~km}$ layers for temperature and better than $15 \%$ in $2 \mathrm{~km}$ layers for water vapour. For the cloud property retrieval we have collocated the AIRS L2 standard products (version 5) with a subset of AIRS L1B radiance measurements which have been downloaded from the NASA data pool (http://mirador.gsfc.nasa.gov).

Temperature and humidity profiles are retrieved from AIRS over a golf ball. The quality of the retrieved atmospheric profiles is only of good quality when the situation is not too cloudy. This is the case in about $50 \%$ of all cloudy situations. In that case, we use an average atmospheric profile in the cloud property retrieval (see Sect. 2.3), obtained from atmospheric profiles of good quality within three days around the day of observation and within $1^{\circ}$ latitude $\times 1^{\circ}$ longitude. In only $2.5 \%$ of all cases, there are not enough atmospheric profiles of good quality within one week, and a monthly mean has to be taken. 


\subsection{AIRS, CALIPSO and L2 Radar-Lidar GEOPROF data and their collocation}

The lidar CALIOP (Winker et al., 2007, 2009) of the CALIPSO mission provides backscatter profiles at $532 \mathrm{~nm}$ and at $1064 \mathrm{~nm}$, at a vertical resolution of about $30 \mathrm{~m}$ below an altitude of $8 \mathrm{~km}$ and $60 \mathrm{~m}$ above an altitude of $8 \mathrm{~km}$. The size of the lidar footprints is about $90 \mathrm{~m} \times 90 \mathrm{~m}$. Horizontal sampling is $333 \mathrm{~m}$ along the track, and the distance between two orbits is about $1000 \mathrm{~km}$. The CALIPSO L2 cloud data (version 2) at $5 \mathrm{~km}$ spatial resolution along the track provide the number of vertical cloud layers and geometrical height of cloud top, $z_{\text {top }}$, and of "apparent" cloud base, $z_{\text {base }}^{\text {app }}$ for each of these layers. The "apparent" cloud base will be higher than the real cloud base in the case of optically thick clouds, because in that case the lidar signal penetrates the cloud only up to an optical depth, $\tau_{\text {cld }}$, of about 5 (Winker et al., 2003). Geometrical height is transformed into cloud top pressure, $p_{\text {top }}$, and "apparent" cloud base pressure, $p_{\text {base }}^{\text {app }}$, using the atmospheric profiles provided by the Global Modelling and Assimilation Office (GMAO) and available in the CALIPSO L1 data. The pressure of the "apparent middle" of the cloud is then: $p_{\text {mid }}=0.5\left(p_{\text {top }}+p_{\text {base }}^{\text {app }}\right)$. In addition, we determine the height of the maximum backscattering signal, $z_{\mathrm{mbsc}}$, at $532 \mathrm{~nm}$ from the backscatter profiles of the CALIPSO L1 data. CALIPSO L2 cloud data also provide cloud optical depth, $\tau_{\text {cld }}$, and a cloud feature flag, which indicates if the cloud is opaque. In that case we have set the cloud optical depth to 5 (D. Winker, personal communication, 2009). The CALIPSO L2 cloud data also indicate at which horizontal averaging the cloud was detected $(1 \mathrm{~km}, 5 \mathrm{~km}, 20 \mathrm{~km}$ or $80 \mathrm{~km})$, which is a measure of the optical thickness of the cloud. For a direct comparison with AIRS data, we use clouds which have been detected at horizontal averaging over $5 \mathrm{~km}$ or less, corresponding to a sensitivity in terms of minimum detectable particle backscatter coefficient of about $0.0008 \mathrm{~km}^{-1} \mathrm{sr}^{-1}$ at night and about $0.0015 \mathrm{~km}^{-1} \mathrm{sr}^{-1}$ during day, for a cirrus with an altitude of about $12 \mathrm{~km}$ (Fig. 4 of Winker et al., 2009). This corresponds to clouds with $\tau_{\text {cld }}$ larger than about 0.05 to 0.1 (Winker et al., 2008). In the following, we refer to these clouds as "clouds not including subvisible cirrus". We only use $\tau_{\text {cld }}$ in Sect. 4 , being aware that this product is still not final and has large uncertainties also due to multiple scattering corrections (e.g. Lamquin et al., 2008). CALIPSO data were obtained through the NASA Atmospheric Sciences Data Center (ASDC) by the ICARE Thematic Center created by CNES (http://www-icare.univ-lille1.fr/) and its interface ClimServ at IPSL (http://climserv.ipsl.polytechnique.fr/).

The cloud profiling radar (CPR) of the CloudSat mission (Stephens et al., 2002; Mace et al., 2007) is capable of probing optically thick cloud layers and therefore provides the correct cloud base. Combined with the information on optically thin cloud layers from CALIOP, these two instruments provide a complete vertical profiling of all clouds. The CPR footprint is about $2.5 \mathrm{~km} \times 1.4 \mathrm{~km}$, and it provides measure- ments at a vertical resolution of about $250 \mathrm{~m}$. The method to merge the geometrical profiling of CALIOP and CPR (Mace et al., 2009) was designed to extract maximum information on cloud layering from the combined radar and lidar sensors. The data (version 3) have been acquired from the CloudSat data processing center (http://www.cloudsat.cira. colostate.edu).

All satellites of the A-Train follow each other within a few minutes. First, CALIPSO cloud properties averaged over $5 \mathrm{~km}$ are combined with the corresponding AIRS footprints in such a way that for each AIRS golf ball $(3 \times 3$ AIRS footprints) three CALIPSO L2 samples are kept, each close to the centre of an AIRS golf ball, as in (Stubenrauch et al., 2008). For our comparisons, we have to keep in mind, however, that CALIPSO provides only a small sample $(5 \mathrm{~km} \times 90 \mathrm{~m})$ of the AIRS footprint $(14 \mathrm{~km} \times 14 \mathrm{~km})$. Even by averaging two to three CALIPSO samples over an AIRS footprint, the sampling stays limited by the very narrow nadir track $(90 \mathrm{~m})$.

In a second step we collocate these data with the complete vertical profiling of the L2 Radar - Lidar GEOPROF data. Therefore, we keep for each CPR footprint $(1.4 \mathrm{~km} \times 2.3 \mathrm{~km})$ the information of the CALIPSO sample and of the corresponding AIRS footprint. We also add information on scene homogeneity, by using clear/cloudy information of the three CALIPSO samples and cloud type information of the nine AIRS footprints within the AIRS golf ball. For the analysis of high clouds in Sect. 4 we only keep situations for which the cloud top height of the CALIPSO sample and cloud top height averaged over the CPR footprint lie within $200 \mathrm{~m}$.

\subsection{AIRS-LMD cloud property retrieval method}

The cloud property retrieval scheme is based on a weighted $\chi^{2}$ method using channels around the $15 \mu \mathrm{m} \mathrm{CO} 2$ absorption band (Stubenrauch et al., 1999a), providing pressure and effective emissivity of a single cloud layer (of the uppermost cloud layer in the case of multi-layer clouds). $\chi^{2}$ is computed by summation over $N$ wavelengths $\lambda_{i}$ of the $\mathrm{CO}_{2}$ absorption band around $15 \mu \mathrm{m}$, as in Eq. (1).

$$
\begin{aligned}
\chi^{2}\left(p_{\mathrm{k}}\right) & =\sum_{i=1}^{N}\left[\left(I_{\mathrm{cld}}\left(p_{\mathrm{k}}, \lambda_{i}\right)-I_{\mathrm{clr}}\left(\lambda_{i}\right)\right) \cdot \varepsilon_{\mathrm{cld}}\left(p_{\mathrm{k}}\right)-\left(I_{\mathrm{m}}\left(\lambda_{i}\right)\right.\right. \\
& \left.\left.-I_{\mathrm{clr}}\left(\lambda_{i}\right)\right)\right]^{2} \cdot W^{2}\left(p_{\mathrm{k}}, \lambda_{i}\right)
\end{aligned}
$$

The measured radiance $I_{\mathrm{m}}$ is obtained from the AIRS L1B data. We have chosen AIRS channels corresponding closely to the five channels used in the TIROS-N Operational Vertical Sounder (TOVS) Path-B cloud retrieval, at wavelengths of $14.190,14.002,13.928,13.279$ and $10.901 \mu \mathrm{m}$, and three additional channels at 14.298, 14.094 and $13.239 \mu \mathrm{m}$ (AIRS channels 174, 193, 210, 226, 239, 355, 362 and 787). The weighting functions of these channels are shown in Fig. 1 as the derivatives of the transmission function with respect to pressure. For this illustration, they have been simulated by the Automatized Atmospheric Absorption Atlas (4A) 
radiative transfer model (Scott and Chédin, 1981; operational version available at http://www.noveltis.net/4AOP) for an average tropical atmosphere.

$I_{\mathrm{clr}}$ is the radiance which would be measured by AIRS in the case of clear sky, and $I_{\text {cld }}$ is the radiance emitted by a homogenous opaque single cloud layer, calculated for 39 assumed cloud pressure levels $p_{\mathrm{k}}$ above surface $(984 \mathrm{hPa}$ to $106 \mathrm{hPa}$ ). For their computation we need the AIRS L2 temperature profiles as well as atmospheric transmissivity profiles at the corresponding wavelengths for an atmospheric situation similar to the one described by the AIRS L2 atmospheric temperature and water vapour profiles (Susskind et al., 2003). These atmospheric spectral transmissivity profiles have been simulated by the $4 \mathrm{~A}$ radiative transfer model, separately for each satellite viewing zenith angle (up to $50^{\circ}$ ) and for about 2000 representative clear sky atmospheric temperature and humidity profiles of the TIGR data base. The proximity recognition between the AIRS L2 atmospheric profiles and the TIGR atmospheric profiles is described in detail in (Stubenrauch et al., 2008). If no simultaneous AIRS L2 atmospheric profile of good quality is available (which may occur if the situation is too cloudy), a running mean average of atmospheric profiles with good quality (Tobin et al., 2006) over one week, at a spatial resolution of $1^{\circ}$ latitude $\times 1^{\circ}$ longitude, is used. The third choice is a monthly mean of atmospheric profiles with good quality, at $1^{\circ}$ latitude $\times 1^{\circ}$ longitude. For the computation of $I_{\mathrm{clr}}$ we also need spectral surface emissivities. These are provided for the latitude band $30^{\circ} \mathrm{N}-30^{\circ} \mathrm{S}$ as climatological monthly averages from three years of AIRS data (Péquignot et al., 2008), at a spatial resolution of $1^{\circ}$ latitude $\times 1^{\circ}$ longitude. For the rest of the globe we use climatological monthly averages from six years of MODIS data (Seemann et al., 2008), at a spatial resolution of $0.5^{\circ}$ latitude $\times 0.5^{\circ}$ longitude, which have then been spectrally interpolated to the AIRS channels.

By introducing empirical weights $W\left(p_{\mathrm{k}}, \lambda_{i}\right)$, the method takes into account 1) the vertical weighting of the different channels, 2) the growing uncertainty in the computation of $\varepsilon_{\text {cld }}$ with increasing $p_{\mathrm{k}}$ and 3) uncertainties in atmospheric profiles. These weights are determined for each of the five TIGR air mass classes (tropical, midlatitude summer and winter, polar summer and winter) as in Eqs. (8) and (10) of (Stubenrauch et al., 1999a). Minimizing $\chi^{2}$ in Eq. (1) is equivalent to $\mathrm{d} \chi^{2} / \mathrm{d} \varepsilon_{\text {cld }}=0$, from which one can extract $\varepsilon_{\text {cld }}$ as:

$$
\begin{aligned}
& \varepsilon_{\mathrm{cld}}\left(p_{\mathrm{k}}\right)= \\
& \frac{\sum_{i=1}^{N}\left[I_{\mathrm{m}}\left(\lambda_{i}\right)-I_{\mathrm{clr}}\left(\lambda_{i}\right)\right] \cdot\left[I_{\mathrm{cld}}\left(p_{\mathrm{k}}, \lambda_{i}\right)-I_{\mathrm{clr}}\left(\lambda_{i}\right)\right] \cdot W^{2}\left(p_{\mathrm{k}}, \lambda_{i}\right)}{\sum_{i=1}^{N}\left[I_{\mathrm{cld}}\left(p_{\mathrm{k}}, \lambda_{i}\right)-I_{\mathrm{clr}}\left(\lambda_{i}\right)\right]^{2} \cdot W^{2}\left(p_{\mathrm{k}}, \lambda_{i}\right)}
\end{aligned}
$$

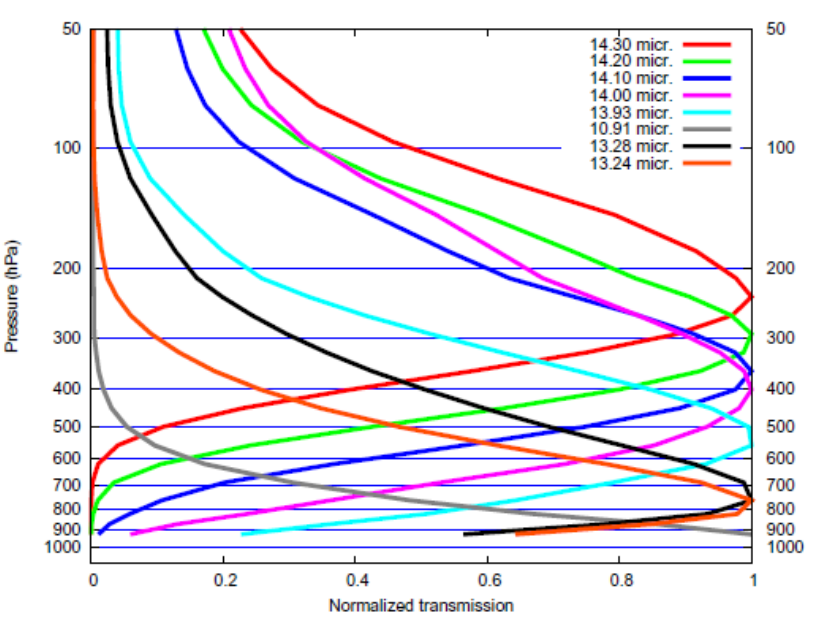

Fig. 1. Weighting functions of eight AIRS channels, from near the centre towards the wing of the $\mathrm{CO}_{2}$ absorption band around $15 \mu \mathrm{m}$, used in the cloud property retrieval.

It is important to allow values larger than 1, because at larger pressure levels $I_{\mathrm{clr}}$ and $I_{\mathrm{cld}}$ become very similar and their uncertainties can lead to values larger than 1 (Stubenrauch et al., 1999a). When the $\chi^{2}$ method leads to a non-acceptable value of $\varepsilon_{\text {cld }}$ (larger than 1.5), the scene is set to clear sky.

Cloud temperature $T_{\text {cld }}$ is determined from $p_{\text {cld }}$, using the AIRS L2 temperature profile. Cloud types are distinguished according to $p_{\text {cld }}$ and $\varepsilon_{\text {cld }}$. High clouds are defined by $p_{\text {cld }}<440 \mathrm{hPa}$, midlevel clouds by $440 \mathrm{hPa}<p_{\text {cld }}<680 \mathrm{hPa}$ and low clouds by $p_{\text {cld }}>680 \mathrm{hPa}$. High clouds may be further distinguished into opaque $\left(\varepsilon_{\mathrm{cld}}>0.95\right)$, cirrus $\left(0.95>\varepsilon_{\text {cld }}>0.50\right)$ and thin cirrus $\left(\varepsilon_{\text {cld }}<0.50\right)$. The transformation of $p_{\text {cld }}$ into cloud altitude $z_{\text {cld }}$ makes use of the virtual temperature profile determined from the AIRS L2 temperature and water vapour profiles.

The retrieval is applied to all AIRS footprints. Then a test based on the spectral coherence of retrieved cloud emissivities decides whether the AIRS footprint is cloudy (overcast or mostly cloudy) or clear (or not cloudy enough to determine reliably the cloud properties). Thresholds have been established by comparing clear and cloudy scenes within the AIRS footprints, distinguished by coincident CALIOP measurements (see next section).

When extending the cloud property retrieval to the whole globe, we have revised the algorithm presented in (Stubenrauch et al., 2008) in several ways:

- Instead of five channels along the $\mathrm{CO}_{2}$ absorption band we now use eight channels.

- Therefore, we have increased the vertical resolution of possible pressure levels for clouds (between $984 \mathrm{hPa}$ and $106 \mathrm{hPa}$ ) from 29 to 39 levels.

- Since the bias corrections between observed and simulated brightness temperatures for the chosen channels 

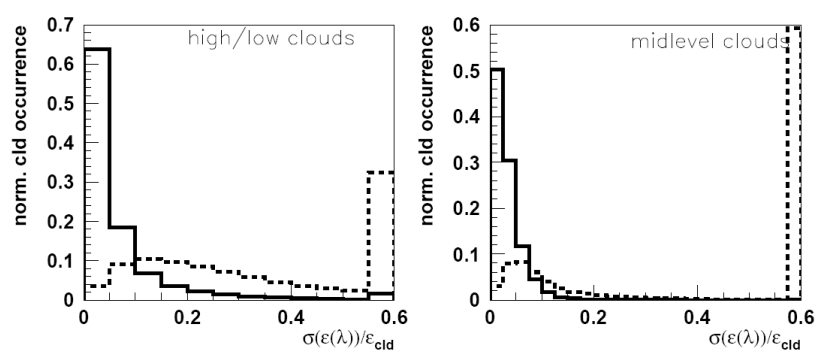

\subsection{Determination of AIRS-LMD clear and cloudy scenes}

To distinguish cloudy from clear sky scenes in a way which does not depend on regionally and seasonally varying cloud detection thresholds, we have developed a method which is applied after the cloud property retrieval. It is based on the spectral coherence of retrieved cloud emissivities. Therefore, for each AIRS footprint cloud emissivities $\varepsilon_{\text {cld }}$ are determined at six wavelengths $\lambda_{i}=11.85,10.90,10.69,10.40$, $10.16,9.12 \mu \mathrm{m}$ as:

$\varepsilon_{\mathrm{cld}}\left(\lambda_{i}\right)=\frac{I_{\mathrm{m}}\left(\lambda_{i}\right)-I_{\mathrm{clr}}\left(\lambda_{i}\right)}{I_{\mathrm{cld}}\left(p_{\mathrm{cld}}, \lambda_{i}\right)-I_{\mathrm{clr}}\left(\lambda_{i}\right)}$

where $I_{\text {cld }}$ is now determined for $p_{\text {cld }}$ which has been retrieved by the $\chi^{2}$ method (see above). When $p_{\text {cld }}$ is well determined, the cloud emissivities should only differ slightly between 9 and $12 \mu \mathrm{m}$. The variability should be larger, when the footprint is partly cloudy or clear and hence the cloud pressure could not be well determined. In this case, the footprint is declared as not cloudy. Figure 2 presents distributions of the standard deviation $\sigma\left(\varepsilon_{\lambda}\right)$ over the six wavelengths divided by the retrieved $\varepsilon_{\text {cld }}$, separately for cloudy scenes and for clear sky scenes as determined by CALIPSO. Cloudy/clear scenes are situations for which all three CALIPSO samples within the AIRS golf ball are cloudy/clear. Distributions are shown for clouds which have been determined by the $\chi^{2}$ method as low or high clouds ( $p_{\text {cld }}>680 \mathrm{hPa}$ or $p_{\text {cld }}<440 \mathrm{hPa}$ ) and separately for clouds determined as midlevel clouds $\left(440 \mathrm{hPa}<p_{\text {cld }}<680 \mathrm{hPa}\right)$ over surfaces not covered by snow or ice as well as for all clouds over snow and ice regions, using observations at 01:30 LT. A microwave flag giving information on snow and ice is provided by the AIRS L2 data. We observe that in general the distributions are narrower for cloudy scenes than for clear sky (or partly cloudy scenes), with a relatively good separation when using a threshold of 0.2 for low and high clouds and of 0.1 for midlevel clouds. However, the discrimination is much less pronounced when the surface is covered by snow or ice. In this case we have explored another variable: the brightness temperature difference between $11 \mu \mathrm{m}$ and an average of four channels around $7 \mu \mathrm{m}$ (at 7.180, 7.183, 7.223 and $7.240 \mu \mathrm{m}$ ). The first wavelength corresponds to an atmospheric window, whereas the latter correspond to the absorption band of water vapour. In general, one would expect positive differences, because the second brightness temperature is reduced by the absorption of water vapour in the atmosphere. In the case of cold temperatures and dry air, predominant in polar regions, atmospheric inversions would lead to a negative difference (Liu and Key, 2003). From Fig. 2 we discriminate cloudy from clear scenes by using a threshold of $-5 \mathrm{~K}$. A similar test is applied in the MODIS cloud retrieval (Frey et al., 2008) during polar night. Indeed, when comparing the distributions for observations at 13:30 LT in Fig. 3, the brightness 

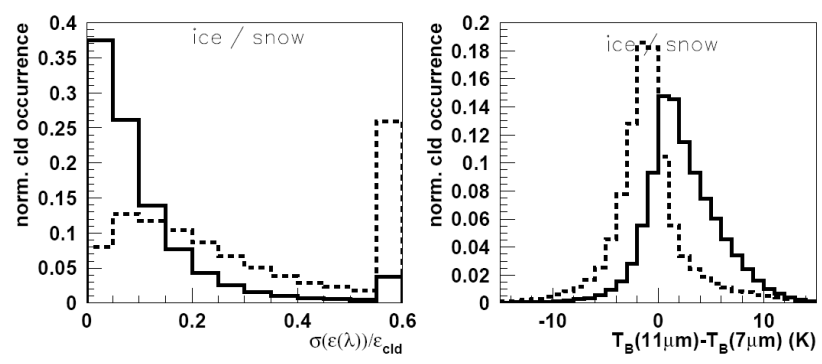

Fig. 3. Same distributions as in lower panels of Fig. 2, but this time for observations at 13:30 LT.

temperature difference is less pertinent, because temperature inversions occur mostly during night and early morning. When applying these thresholds, we observed that especially over land there were clouds with a temperature close to the surface air temperature. By exploring distributions of $T_{\text {cld }}-T_{\text {surf }}$ (air) (not shown), we discovered that these scenes correspond mostly to CALIPSO clear sky scenes. Therefore, we apply over land an additional test which resets to clear sky all cloudy situations with $T_{\text {cld }}-T_{\text {surf }}$ (air) $>-3 \mathrm{~K}$.

In the following, we summarize the tests for the AIRSLMD cloud detection.

The AIRS footprint is cloudy if the following conditions are fulfilled:

$$
\varepsilon_{\text {cld }}>0.05
$$

for regions not covered by snow or sea ice:

$$
\begin{aligned}
& \sigma\left(\varepsilon_{\lambda}\right) / \varepsilon_{\text {cld }}<0.2 \text { if } p_{\text {cld }}<440 \mathrm{hPa} \text { or } p_{\text {cld }}>680 \mathrm{hPa} \\
& \sigma\left(\varepsilon_{\lambda}\right) / \varepsilon_{\text {cld }}<0.1 \text { if } 440 \mathrm{hPa}<p_{\text {cld }}<680 \mathrm{hPa}
\end{aligned}
$$

or for regions covered by snow or sea ice:

$$
\begin{aligned}
& T B(11 \mu \mathrm{m})-T B(7 \mu \mathrm{m})>-5 \mathrm{~K} \\
& \sigma\left(\varepsilon_{\lambda}\right) / \varepsilon_{\mathrm{cld}}<0.3
\end{aligned}
$$

and over land or snow:

$$
T_{\text {cld }}-T_{\text {surf }}(\text { air })<-3 \mathrm{~K} \text {. }
$$

This "a posteriori" cloud detection leads to an agreement with the CALIPSO cloud detection (at a horizontal averaging of $5 \mathrm{~km}$ or less) of about $82 \% / 88 \% / 88 \%$ over ocean and $82 \% / 80 \% / 84 \%$ over land, respectively in tropical latitudes, midlatitudes and polar latitudes and of about $80 \% / 76 \%$ over sea ice and 75\%/69\% over snow, respectively in midlatitudes and polar latitudes for observations at 01:30 LT. In general these agreements are quite high, especially if we consider that CALIPSO only samples the AIRS footprint. They are slightly higher over ocean than over land. Table 1 summa-

\begin{tabular}{|c|c|c|c|c|}
\hline \multicolumn{5}{|c|}{ a) over ocean and land observation time 01:30 LT 13:30 LT } \\
\hline observation time & 01: & LT & 13: & LT \\
\hline latitude bands surface & ocean & land & ocean & land \\
\hline tropic: & $82.0 \%$ & $81.9 \%$ & $77.7 \%$ & $85.2 \%$ \\
\hline midlatitudes & $87.7 \%$ & $79.5 \%$ & $86.7 \%$ & $83.4 \%$ \\
\hline polar & $88.4 \%$ & $83.5 \%$ & $88.9 \%$ & $81.0 \%$ \\
\hline
\end{tabular}
rizes this agreement separately for 01:30 LT and 13:30 LT.

\begin{tabular}{|c|c|c|c|c|}
\hline \multicolumn{5}{|c|}{ b) over sea ice and snow covered land } \\
\hline observation time & \multicolumn{2}{|c|}{ 01:30 LT } & \multicolumn{2}{|c|}{ 13:30 LT } \\
\hline latitude bands surface & sea ice & snow & sea ice & snow \\
\hline midlatit & $80.2 \%$ & $74.9 \%$ & $83 / 9 \%$ & $77.6 \%$ \\
\hline polar & $76.4 \%$ & $68.7 \%$ & $83.2 \%$ & $68.3 \%$ \\
\hline
\end{tabular}
This kind of comparison was considered to determine the thresholds, in addition to the study of geographical maps
Table 1. Agreement of clear and cloudy scenes determined by the AIRS "a posteriori" cloud detection and by CALIPSO.

c) comparison using a threshold of $-2 \mathrm{~K}$ instead of $-5 \mathrm{~K}$

$$
\text { 01:30 LT } 13: 30 \mathrm{LT}
$$

\begin{tabular}{llllll}
\hline & surface & sea ice & snow & sea ice & snow \\
\cline { 1 - 5 } latitude bands & & & & \\
\hline midlatitudes & $80.3 \%$ & $76.0 \%$ & $83.0 \%$ & $78.2 \%$ \\
polar & $77.5 \%$ & $68.5 \%$ & $82.3 \%$ & $70.4 \%$ \\
\hline
\end{tabular}

and latitudinal dependence (as in Figs. 6 and 7). In Table 1 we also present as an example the agreement when changing the test from $T B(11 \mu \mathrm{m})-T B(7 \mu \mathrm{m})>-5 \mathrm{~K}$ to $T B(11 \mu \mathrm{m})$ $-T B(7 \mu m)>-2 \mathrm{~K}$. The agreement is similar, but when considering the latitudinal dependence of cloud amount which shows already a small cloud amount in the polar regions, the latter threshold yields a still smaller cloud amount in the polar regions.

\subsection{Evaluation of AIRS-LMD cloud height}

We have analyzed two years (2007-2008) of collocated AIRS CALIPSO data, separately for three latitude bands: tropical/subtropical latitudes $\left(30^{\circ} \mathrm{N}-30^{\circ} \mathrm{S}\right)$, midlatitudes $\left(30^{\circ} \mathrm{N}-60^{\circ} \mathrm{N}\right.$ and $\left.30^{\circ} \mathrm{S}-60^{\circ} \mathrm{S}\right)$ and polar latitudes $\left(60^{\circ} \mathrm{N}-\right.$ $90^{\circ} \mathrm{N}$ and $\left.60^{\circ} \mathrm{S}-90^{\circ} \mathrm{S}\right)$. Figure 4 presents normalized distributions of $p_{\text {cld }}$ (AIRS) $-p_{\text {mid }}($ CALIPSO), using cloud layers detected by CALIPSO, not including subvisible cirrus (see Sect. 2.2). In the case of multiple cloud layers we choose the one which is closest in height between the highest and second highest, as in (Stubenrauch et al., 2008). This is justified, because CALIPSO only sparsely samples the AIRS footprint, and AIRS could observe a mixture of both clouds. We compare the results of the AIRS-LMD cloud retrieval to those provided by the NASA AIRS L2 data. In general, all AIRS-LMD distributions peak around 0. The distribution in the polar latitudes is broader, most probably because the cloud height determination is less precise over snow and 


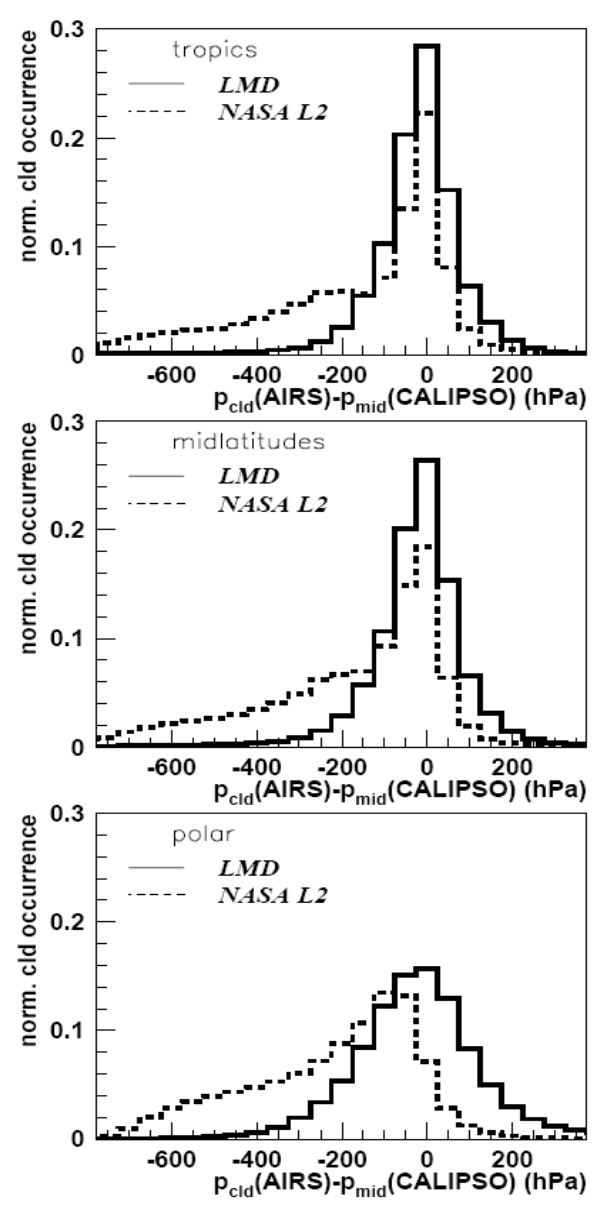

Fig. 4. Normalized frequency distributions of the difference between AIRS cloud pressure and pressure of the "apparent middle" of the uppermost cloud layer detected by CALIPSO, excluding subvisible cirrus. Observations at 01:30 LT. AIRS cloud retrievals from LMD are compared to those of NASA L2 products, separately for the latitude bands $30^{\circ} \mathrm{N}-30^{\circ} \mathrm{S}$ (upper panel), $30^{\circ}-60^{\circ}$ (middle panel) and $60^{\circ}-90^{\circ}$ (lower panel).

ice surfaces. Distributions for the NASA L2 cloud pressure also peak around 0 , but they have large tails towards negative values. The range of retrieved $p_{\text {cld }}$ is much smaller than for AIRS-LMD, with large negative biases for low clouds. These biases have already been revealed in (Kahn et al., 2008; Stubenrauch et al., 2008). In polar latitudes the peak is even shifted to $-100 \mathrm{hPa}$ and the tail is even larger.

In Fig. 5 we compare the AIRS-LMD cloud height with the height of the maximum backscatter signal within the cloud, determined by CALIPSO, separately for high clouds and for midlevel/low clouds. We observe that in all three latitude bands the difference distributions once again have a peak around 0 and distributions for midlevel/low clouds are slightly narrower than for high clouds. This can be explained by the fact that for midlevel/low clouds $z_{\text {mbsc }}$ is close to $z_{\text {top }}$, whereas high clouds can be much more diffuse, leading to much broader distributions of $z_{\text {top }}-z_{\text {mbsc }}$, as seen in the right
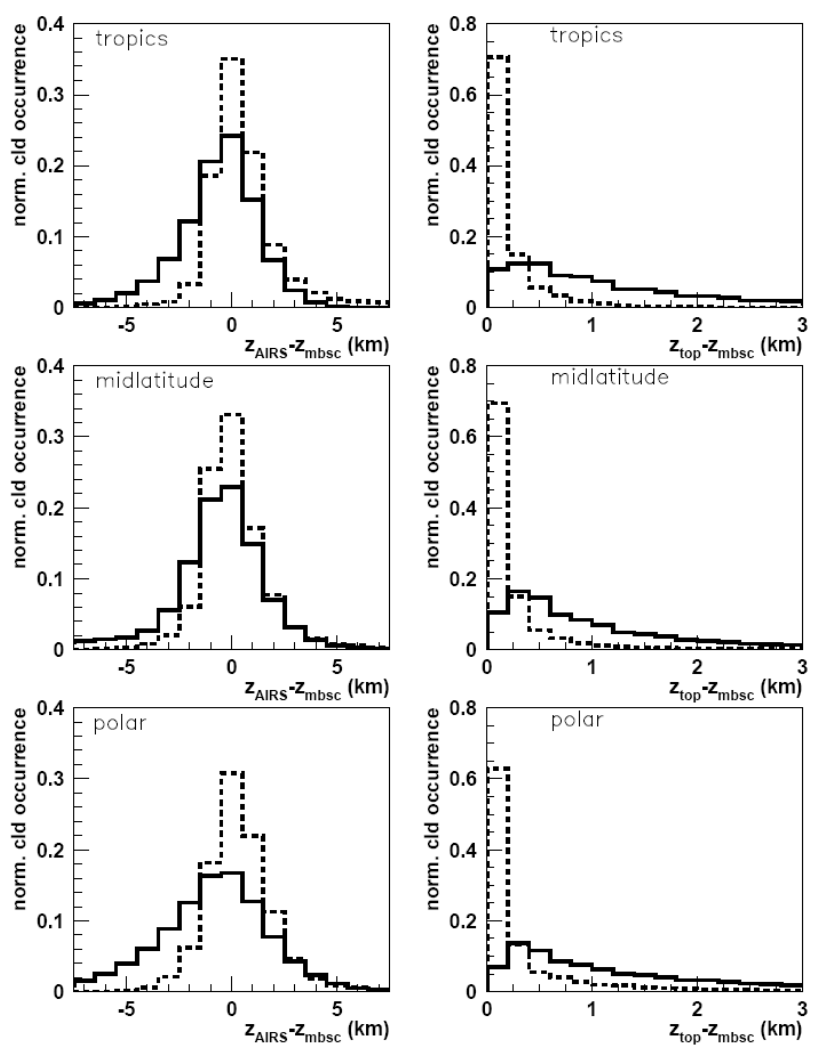

Fig. 5. Normalized frequency distributions of the difference between the cloud height of AIRS-LMD and the height of maximum backscatter of the uppermost cloud layer detected by CALIPSO, excluding subvisible cirrus, (left) and the difference between cloud top and height of maximum backscatter (right), separately for high clouds (full line) and midlevel/low clouds (broken line) as determined by CALIPSO, for the latitude bands $30^{\circ} \mathrm{N}-30^{\circ} \mathrm{S}$ (upper panels), $30^{\circ}-60^{\circ}$ (middle panels) and $60^{\circ}-90^{\circ}$ (lower panels).

panel of Fig. 5. When considering cases in which a running mean atmospheric profile within one week has been used in the cloud retrieval, the distributions look very similar. Only in the $2.5 \%$ of all cases with a monthly mean atmosphere, there seems to be a slight negative bias of about $50 \mathrm{hPa}$ in the AIRS-LMD cloud pressure (not shown).

\section{Average cloud properties from 2003 to 2008}

In this section we give a short overview of physical cloud properties obtained from the AIRS-LMD cloud climatology. We concentrate on total cloud amount (CA) as well as on high cloud amount (HCA, clouds with $p_{\text {cld }}<440 \mathrm{hPa}$ ), midlevel cloud amount (MCA, $440 \mathrm{hPa}<p_{\text {cld }}<680 \mathrm{hPa}$ ) and low-level cloud amount (LCA, $\left.p_{\text {cld }}>680 \mathrm{hPa}\right)$. Cloud amount is computed as the ratio of the number of cloudy AIRS footprints and the total number of AIRS measurements per $1^{\circ}$ latitude $\times 1^{\circ}$ longitude. Table 2 presents 6 -year averages of these cloud amounts over the whole globe, over ocean 
Table 2. Cloud amount from the AIRS-LMD cloud climatology, determined as the fraction of cloudy AIRS spots (not cloudy spots have a weight of 0 ). Results are also shown when in the computation not cloudy AIRS footprints are added with a weight of 0.3 (meaning that not cloudy footprints have on average $30 \%$ cloud). For further comparison are shown results from the TOVS Path-B cloud climatology (1987-1995), and results using CALIPSO considering only uppermost layers, once excluding subvisible cirrus and once including them. Averages are shown over the globe, separately over ocean and over land, and over $\mathrm{NH}$ midlatitudes $\left(30^{\circ} \mathrm{N}-60^{\circ} \mathrm{N}\right)$, tropics $\left(15^{\circ} \mathrm{S}-15^{\circ} \mathrm{N}\right)$ and $\mathrm{SH}$ midlatitudes $\left(30^{\circ} \mathrm{S}-60^{\circ} \mathrm{S}\right)$ : a) total (CA), b) high, c) midlevel and d) lowlevel.

\begin{tabular}{|c|c|c|c|c|c|}
\hline $\begin{array}{l}\text { Latitude } \\
\text { band }\end{array}$ & $\begin{array}{r}\text { AIRS-LMD } \\
\text { not cldy }=0\end{array}$ & $\begin{array}{l}\text { AIRS-LMD } \\
\text { not cldy }=0.3\end{array}$ & $\begin{array}{l}\text { TOVS Path-B } \\
\text { climatology }\end{array}$ & $\begin{array}{l}\text { CALIPSO } \\
\text { upper clds }\end{array}$ & $\begin{array}{r}\text { CALIPSO upper } \\
\text { clds+subvis } \mathrm{Ci}\end{array}$ \\
\hline \multicolumn{6}{|l|}{ a) $\mathrm{CA}(\%)$} \\
\hline Global & 66 & 74 & 70 & 70 & 80 \\
\hline Global - ocean & 71 & 76 & 74 & 74 & 85 \\
\hline Global - land & 56 & 65 & 60 & 59 & 70 \\
\hline $60^{\circ} \mathrm{N}-30^{\circ} \mathrm{N}$ & 68 & 75 & 68 & 67 & 76 \\
\hline $15^{\circ} \mathrm{N}-15^{\circ} \mathrm{S}$ & 66 & 72 & 69 & 71 & 86 \\
\hline $30^{\circ} \mathrm{S}-60^{\circ} \mathrm{S}$ & 78 & 83 & 83 & 82 & 88 \\
\hline \multicolumn{6}{|l|}{ b) $\mathrm{HCA} / \mathrm{CA}(\%)$} \\
\hline Global & 40 & 36 & 43 & 42 & 50 \\
\hline Global - ocean & 37 & 32 & 40 & 39 & 46 \\
\hline Global - land & 46 & 43 & 50 & 52 & 60 \\
\hline $60^{\circ} \mathrm{N}-30^{\circ} \mathrm{N}$ & 39 & 34 & 41 & 45 & 51 \\
\hline $15^{\circ} \mathrm{N}-15^{\circ} \mathrm{S}$ & 58 & 55 & 62 & 57 & 66 \\
\hline $30^{\circ} \mathrm{S}-60^{\circ} \mathrm{S}$ & 28 & 26 & 30 & 34 & 39 \\
\hline \multicolumn{6}{|l|}{ c) $\mathrm{MCA} / \mathrm{CA}(\%)$} \\
\hline Global & 18 & 16 & 20 & 16 & 12 \\
\hline Global - ocean & 16 & 13 & 16 & 13 & 9 \\
\hline Global - land & 24 & 22 & 28 & 25 & 19 \\
\hline $60^{\circ} \mathrm{N}-30^{\circ} \mathrm{N}$ & 22 & 19 & 24 & 19 & 15 \\
\hline $15^{\circ} \mathrm{N}-15^{\circ} \mathrm{S}$ & 11 & 9 & 10 & 10 & 5 \\
\hline $30^{\circ} \mathrm{S}-60^{\circ} \mathrm{S}$ & 21 & 18 & 19 & 16 & 13 \\
\hline \multicolumn{6}{|l|}{ d) $\mathrm{LCA} / \mathrm{CA}$} \\
\hline Global & 42 & 47 & 44 & 42 & 38 \\
\hline Global - ocean & 47 & 56 & 50 & 48 & 44 \\
\hline Global - land & 31 & 34 & 30 & 24 & 22 \\
\hline $60^{\circ} \mathrm{N}-30^{\circ} \mathrm{N}$ & 39 & 45 & 39 & 36 & 34 \\
\hline $15^{\circ} \mathrm{N}-15^{\circ} \mathrm{S}$ & 31 & 36 & 34 & 34 & 28 \\
\hline $30^{\circ} \mathrm{S}-60^{\circ} \mathrm{S}$ & 51 & 56 & 52 & 51 & 46 \\
\hline
\end{tabular}

and over land, in the midlatitudes $\left(30^{\circ} \mathrm{N}-60^{\circ} \mathrm{N}\right.$ and $30^{\circ} \mathrm{S}-$ $\left.60^{\circ} \mathrm{S}\right)$ and in the inner tropics $\left(15^{\circ} \mathrm{N}-15^{\circ} \mathrm{S}\right)$. An AIRS footprint is either cloudy $(\mathrm{CA}=100 \%)$ or not cloudy $(\mathrm{CA}=0 \%)$. Because of the relatively large size of the AIRS footprints, it is more likely that not cloudy AIRS footprints are on average partly covered by clouds instead of being completely clear. Therefore, we also present as an example (second column) cloud amounts which have been calculated by adding the not cloudy AIRS footprints with a weight of 0.3 (corresponding to about $30 \%$ cloud amount on average) to the cloudy footprints. This leads to a rise of global cloud amount from $66 \%$ to $74 \%$ and to a larger proportion of low clouds. This assumption of $30 \%$ seems to be feasible as an upper limit, be- cause the total cloud amount lies now between the one determined by CALIPSO including subvisible cirrus and excluding subvisible cirrus. The value of partial cloud coverage strongly depends on the cloud regime, as has been demonstrated by a study of Wielicki et al. (1992).

Globally, there are about 10 to $15 \%$ more clouds over ocean than over land. $42 \%$ of all clouds are high clouds, and about $42 \%$ of all clouds are single layer low-level clouds. The largest fraction of high clouds is situated in the tropics and the largest fraction of single layer low-level clouds in the Southern hemisphere midlatitudes. Only about $10 \%$ of all clouds in the tropics are single layer midlevel clouds. 
$\mathrm{CA}$
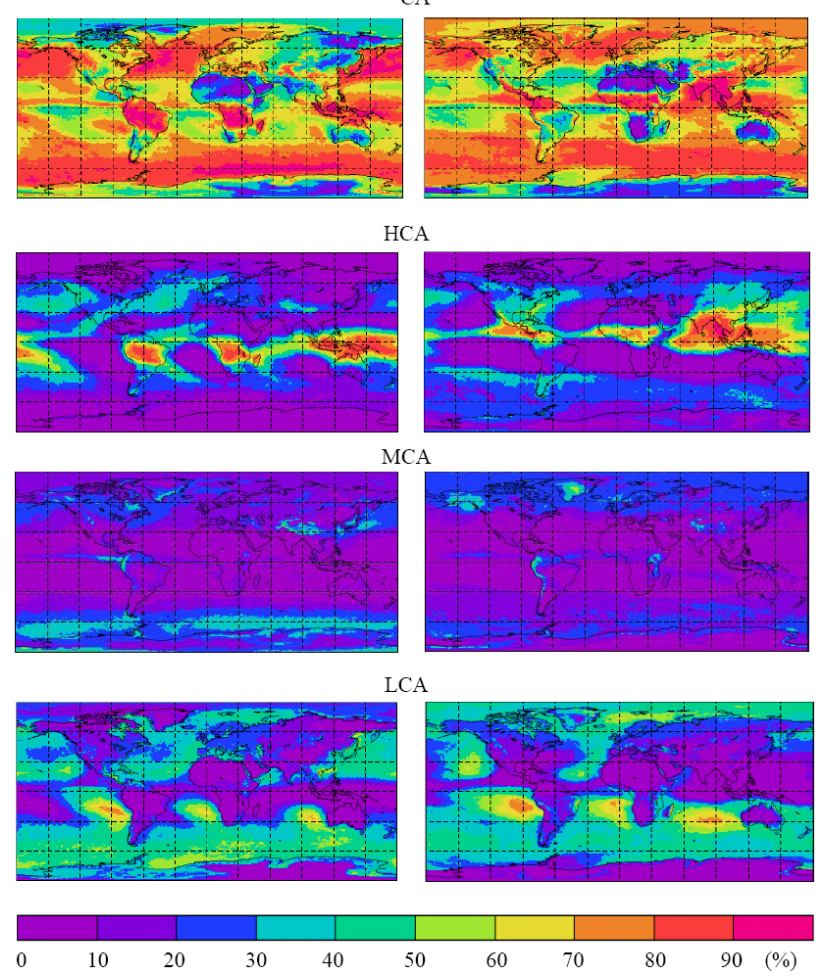

Fig. 6. Geographical maps of total, high, midlevel and low cloud amount from AIRS-LMD, in January (left) and in July (right). Averages over the period from 2003 to 2008.

For comparison, Table 2 also shows results from the TOVS Path-B cloud climatology (1987-1995; Scott et al., 1999; Stubenrauch et al. 2006) as well as from an analysis of CALIPSO L2 cloud data (2007-2008). When determining the CALIPSO cloud amounts, we have counted only the highest cloud layer in the case of multi-layer clouds, once for all detected clouds, including subvisible cirrus, and once excluding subvisible cirrus. Results from TOVS Path-B and CALIPSO, when excluding subvisible cirrus, are very similar. When including the detection of subvisible cirrus, the lidar of CALIPSO yields globally $10 \%$ more cloud amount.

From Table 3 we conclude that seasonal differences are larger in the $\mathrm{NH}$ midlatitudes than in the $\mathrm{SH}$ midlatitudes, with about $4 \%$ to $8 \%$ more clouds in winter, according to CALIPSO or to AIRS and TOVS. This can be probably linked to more land masses in the Northern Hemisphere, where there are slightly more midlevel clouds in winter and more high clouds in summer. Since seasonal differences in the SH midlatitudes are negligible, this leads to much more clouds in the SH than in the NH midlatitudes in summer (about $15 \%$ ), whereas there are only 5 to $10 \%$ more clouds in winter. Considering the different cloud climatologies, gives an idea of the spread of the results and therefore indicates an uncertainty.
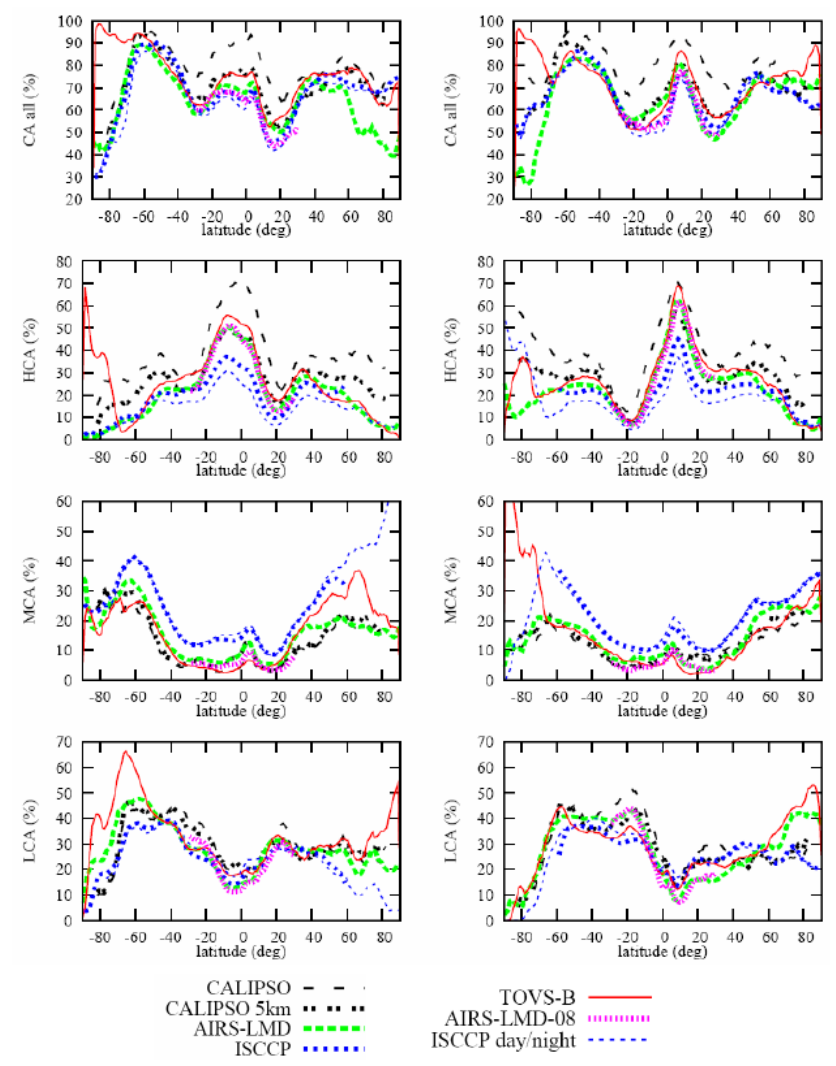

Fig. 7. Zonal averages of total, high, midlevel and low-level cloud amount from AIRS-LMD compared to results from various cloud climatologies, in January (left) and in July (right).

Figure 6 presents geographical maps of CA, HCA, MCA and LCA, for January and for July. The major features of global cloudiness that have been known since the beginning of the satellite era (and in fact, even before that) are also found in this dataset. We also observe large single layer lowlevel cloud amount in the stratocumulus regions off the West coasts of the continents, even if this type of cloud is easier to detect by using instruments including visible channels (during daytime) or active instruments. The transition from stratus towards stratocumulus will be further investigated as in a study by Sandu et al. (2010).

For a more detailed comparison with other cloud climatologies, we present in Fig. 7 latitudinal averages of these cloud amounts, again for January and July. Averages of six years AIRS-LMD (2003-2008) are compared to those of two years CALIPSO (2007-2008; all clouds, including subvisible cirrus, and clouds excluding subvisible cirrus), as well as to averages of eight years TOVS Path-B (19871995). Cloud detection of TOVS Path-B is based on spectral IR brightness temperature differences, also in comparison with those from the Microwave Sounding Unit (MSU). In addition, we present cloud amount averages of ISCCP (Rossow and Schiffer, 1999) for the period 1984-2004. Data 
Table 3. Cloud amount averaged over $\mathrm{NH}$ midlatitudes $\left(30^{\circ} \mathrm{N}-60^{\circ} \mathrm{N}\right)$ in winter, and differences between winter and summer in $\mathrm{NH}$ midlatitudes, winter and summer in SH midlatitudes $\left(30^{\circ} \mathrm{S}-60^{\circ} \mathrm{S}\right)$, between $\mathrm{NH}$ midlatitudes and $\mathrm{SH}$ midlatitudes winter and between $\mathrm{NH}$ midlatitudes and SH midlatitudes summer. Results are shown from AIRS-LMD, TOVS Path-B and CALIPSO as in Table 2: a) total (CA), b) high, c) midlevel and d) lowlevel.

\begin{tabular}{|c|c|c|c|c|c|}
\hline $\begin{array}{l}\text { Latitude } \\
\text { band }\end{array}$ & $\begin{array}{r}\text { AIRS-LMD } \\
\text { not cldy }=0\end{array}$ & $\begin{array}{r}\text { AIRS-LMD } \\
\text { not cldy }=0.3\end{array}$ & $\begin{array}{r}\text { TOVS Path-B } \\
\text { climatology }\end{array}$ & $\begin{array}{l}\text { CALIPSO } \\
\text { upper clds }\end{array}$ & $\begin{array}{l}\text { CALIPSO upper } \\
\text { clds+subvis } \mathrm{C}\end{array}$ \\
\hline \multicolumn{6}{|l|}{ a) $\mathrm{CA}$} \\
\hline $\mathrm{N}$ win & 71 & 79 & 72 & 70 & 78 \\
\hline $\mathrm{N}$ win - sum & 8 & 9 & 8 & 4 & 4 \\
\hline $\mathrm{S}$ win - sum & -3 & -2 & 0 & 1 & -2 \\
\hline $\mathrm{N}-\mathrm{S}$ win & -5 & -2 & -10 & -11 & -9 \\
\hline $\mathrm{N}-\mathrm{S}$ sum & -16 & -13 & -18 & -14 & -15 \\
\hline \multicolumn{6}{|l|}{ b) $\mathrm{HCA} / \mathrm{CA}$} \\
\hline $\mathrm{N}$ win & 35 & 30 & 34 & 42 & 47 \\
\hline $\mathrm{N}$ win - sum & -8 & -8 & -13 & -2 & -4 \\
\hline$S$ win - sum & -4 & -2 & 3 & -3 & -2 \\
\hline $\mathrm{N}-\mathrm{S}$ win & 9 & 5 & 2 & 10 & 10 \\
\hline $\mathrm{N}-\mathrm{S}$ sum & 13 & 11 & 18 & 9 & 12 \\
\hline \multicolumn{6}{|l|}{ c) $\mathrm{MCA} / \mathrm{CA}$} \\
\hline $\mathrm{N}$ win & 25 & 22 & 32 & 19 & 16 \\
\hline $\mathrm{N}$ win - sum & 6 & 5 & 14 & 1 & 1 \\
\hline $\mathrm{S}$ win - sum & 1 & 1 & 0 & -1 & -1 \\
\hline $\mathrm{N}-\mathrm{S}$ win & 4 & 4 & 13 & 4 & 4 \\
\hline $\mathrm{N}-\mathrm{S}$ sum & -1 & 0 & -1 & 2 & 2 \\
\hline \multicolumn{6}{|l|}{ d) $\mathrm{LCA} / \mathrm{CA}$} \\
\hline $\mathrm{N}$ win & 40 & 47 & 36 & 38 & 35 \\
\hline $\mathrm{N}$ win - sum & 3 & 3 & -4 & 2 & 2 \\
\hline$S$ win - sum & 1 & 1 & -4 & 5 & 3 \\
\hline $\mathrm{N}-\mathrm{S}$ win & -12 & -10 & -14 & -15 & -15 \\
\hline $\mathrm{N}-\mathrm{S}$ sum & -14 & -12 & -14 & -12 & -14 \\
\hline
\end{tabular}

and documentation are available at http://isccp.giss.nasa.gov. We have analyzed the monthly D2 statistics (Rossow et al., 1996). CA is given in the D2 data set after interpolation between daytime and nighttime observations. Cloud type determination is more reliable during daytime than during night, because by using "IR only" measurements semi-transparent cirrus are classified as midlevel or low-level clouds (Jin and Rossow, 1997; Stubenrauch et al., 1999b). Therefore, we present in Fig. 7 for ISCCP HCA, MCA and LCA daytime results as well as results obtained from averages over all observations.

Even if sampling (CALIPSO) and observation times (TOVS Path-B 07:30 and 19:30 LT; ISCCP three hourly) differ, the latitudinal behaviour of all data sets agree quite well, except the very high cloud amount from TOVS Path-B over Antarctica. Compared to CALIPSO data in this region, the TOVS Path-B cloud amount appears too high. AIRS-LMD underestimates CA in polar latitudes in winter. These regions are the most difficult for cloud detection, because of the small contrast between clouds and surface. ISCCP determines well $\mathrm{CA}$ in these regions because of the additional use of the $3.7 \mu \mathrm{m}$ channel of the Advanced Very High Resolution Radiometer (AVHRR). Between $60^{\circ} \mathrm{N}$ and $60^{\circ} \mathrm{S} \mathrm{CA}$ of all climatologies is quite similar to CA determined by CALIPSO when excluding subvisible cirrus. The cloud type amount differences can be explained by instrument sensitivities: HCA of CALIPSO is about $10 \%$ larger than HCA of CALIPSO for clouds excluding subvisible cirrus. In the tropics, the difference can be as large as $20 \%$, suggesting that these regions are covered by more thin cirrus (e.g. Wang et al., 1996; Winker and Trepte, 1998). For all three cloud types AIRS-LMD and TOVS Path-B agree quite well with CALIPSO clouds when excluding subvisible cirrus. Daytime cloud type amounts from ISCCP are missing in the winter hemisphere at latitudes higher than $60^{\circ}$, because of permanent lack of daylight. Compared to the results from the IR sounder cloud climatologies, ISCCP daytime HCA is about $15 \%$ lower in the tropics, due to misidentification of 
thin cirrus. When combining ISCCP day and night observations the difference in HCA between IR sounders and IS$\mathrm{CCP}$ increases to $20 \%$ in the tropics. Especially if thin cirrus is overlying low clouds, this cloud type is misidentified as midlevel or low-level cloud (Jin and Rossow, 1997; Stubenrauch et al., 1999b). Therefore MCA of ISCCP appears 5 to $10 \%$ larger than that of CALIPSO. In the polar latitudes during winter, the ISCCP MCA is up to $20 \%$ larger than the one of CALIPSO.

At last we present in Fig. 8 zonally averaged vertical distributions of relative cloud amount as obtained from AIRSLMD, from CALIPSO (once considering only uppermost cloud layers and once considering all vertical cloud layers, in both cases subvisible cirrus are excluded) and from Radar - Lidar GEOPROF, separately for boreal winter (left) and boreal summer (right). The CALIPSO cloud amount is presented at the height of maximum backscatter and the Radar - Lidar GEOPROF cloud amount at the height of the middle of the cloud. The data are normalized in such a way that the sum over all heights for each latitude interval corresponds to $100 \%$. We have to keep in mind that AIRS-LMD provides only information on the uppermost cloud layers, whereas for CALIPSO and Radar-Lidar GEOPROF we have used the information on all vertical cloud layers. Therefore the features from AIRS-LMD compare better to those from CALIPSO for the uppermost cloud layer. However, low-level clouds from the AIRS-LMD climatology seem to be situated slightly lower than those observed by CALIPSO, probably because of partly covered cloud fields. When considering all vertical cloud layers, the fraction of low clouds increases slightly, and slightly more with Radar - Lidar GEOPROF data. As indicated in (Mace et al., 2009), dense aerosol layers may be misidentified as low-level clouds by CALIPSO and there may be a surface contamination in the radar data (Mace et al., 2007), leading to an overestimation of low clouds. Nevertheless, features from the different data sets look quite similar, which indicates that low-level clouds also appear as single layer clouds. All data sets show well the structure of the ITCZ with high clouds near the tropopause and only few low-level clouds. The maximum of relative cloud amount from AIRS-LMD seems to be slightly lower than the one by CALIPSO or Radar - Lidar GEOPROF, because in the case of thin cirrus and thicker cirrus underneath, AIRS-LMD determines the cloud height of the cloud underneath, whereas the other data sets account for both cloud layers. Other interesting features in the midlatitudes are the winter storm tracks for which AIRS-LMD shows a full cloud column in contrast to cirrus in summer. At polar latitudes (especially over Antarctica) in winter CALIPSO detects stratospheric clouds (as observed for example by Sassen et al., 2008) which are not determined by AIRS-LMD.
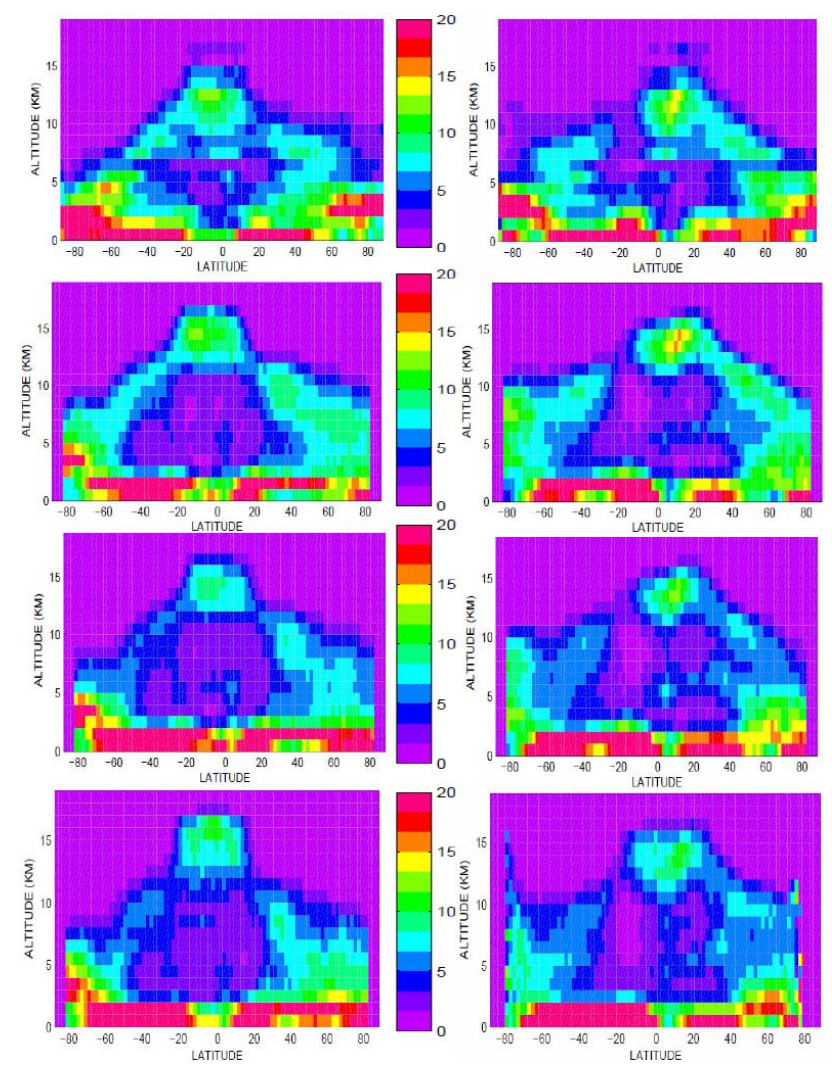

Fig. 8. Zonally averaged vertical distributions of relative cloud amount as obtained from AIRS-LMD (top panel), from CALIPSO (once for the uppermost cloud layer and once for all vertical cloud layers, in both cases subvisible cirrus excluded) and from Radar Lidar GEOPROF (bottom panel), separately for boreal winter (left) and boreal summer (right). The data are normalized in such a way that the sum over all heights for each latitude interval corresponds to $100 \%$. Averages over the period from 2007 to 2008 .

\section{Synergy of AIRS, CALIPSO and CloudSat: properties of high clouds}

In this section we further explore the properties of high clouds, by distinguishing opaque clouds, cirrus and thin cirrus (see Sect. 2.3). First, we are interested in their occurrence, summarized in Table 4 . Whereas high opaque clouds cover only a very small area of about $3 \%$, cirrus and thin cirrus have each about a four times larger coverage. Values of AIRS-LMD and of TOVS Path-B are quite similar, with slightly more high opaque clouds and slightly less cirrus from AIRS, especially in the tropics. This is certainly linked to the better spatial resolution of $13.5 \mathrm{~km}$ for the AIRS-LMD cloud retrieval compared to $100 \mathrm{~km}$ for TOVS Path-B.

The following sections illustrate how the synergy between AIRS, CALIPSO and CloudSat leads to more insight of the vertical structure of these different cloud types. Therefore we use the collocated AIRS, CALIPSO and CloudSat data set (see Sect. 2.2), which provides, amongst other parameters, 
Table 4. Cloud amount (CA) of high opaque clouds ( $p_{\text {cld }}<440 \mathrm{hPa}$ and $\left.\varepsilon_{\text {cld }}>0.95\right)$, cirrus $\left(p_{\text {cld }}<440 \mathrm{hPa}\right.$ and $\left.0.5>\varepsilon_{\text {cld }}>0.95\right)$, and thin cirrus $\left(p_{\text {cld }}<440 \mathrm{hPa}\right.$ and $\left.\varepsilon_{\text {cld }}<0.5\right)$, from the AIRS-LMD cloud climatology. For comparison, results are shown in italic from the TOVS Path-B cloud climatology (1987-1995). Averages are presented over the globe, separately over ocean and over land, and over $\mathrm{NH}$ midlatitudes $\left(30^{\circ} \mathrm{N}-60^{\circ} \mathrm{N}\right)$, tropics $\left(15^{\circ} \mathrm{S}-15^{\circ} \mathrm{N}\right)$ and $\mathrm{SH}$ midlatitudes $\left(30^{\circ} \mathrm{S}-60^{\circ} \mathrm{S}\right)$.

\begin{tabular}{lccc}
\hline Latitude band & High opaque CA & Cirrus CA & Thin Ci CA \\
\hline Global & 3.12 .4 & $12.2 \mathbf{1 3 . 8}$ & $12.6 \mathbf{1 2 . 5}$ \\
Global - ocean & $3.0 \mathbf{1 . 9}$ & $11.8 \mathbf{1 3 . 7}$ & $12.3 \mathbf{1 2 . 8}$ \\
Global - land & $3.3 \mathbf{3 . 7}$ & $13.2 \mathbf{1 4 . 6}$ & $13.4 \mathbf{1 2 . 3}$ \\
$60^{\circ} \mathrm{N}-30^{\circ} \mathrm{N}$ & 3.22 .9 & $13.6 \mathbf{1 4 . 0}$ & $10.4 \mathbf{1 0 . 2}$ \\
$15^{\circ} \mathrm{N}-15^{\circ} \mathrm{S}$ & $4.5 \mathbf{2 . 4}$ & $16.7 \mathbf{2 0 . 1}$ & $20.9 \mathbf{2 1 . 1}$ \\
$30^{\circ} \mathrm{S}-60^{\circ} \mathrm{S}$ & $3.2 \mathbf{2 . 3}$ & $11.9 \mathbf{1 4 . 1}$ & $7.6 \mathbf{7 . 2}$ \\
\hline
\end{tabular}

cloud type identification and "radiative" cloud height by AIRS, cloud top, height of maximum backscatter signal and "apparent" cloud base by CALIPSO as well as cloud top and "real" cloud base by CloudSat.

In the first subsection we will explore the position of the maximum backscatter signal within the cloud as well as the "apparent" and geometrical thickness of the different cloud types. A characterization of cloud boundaries is needed to specify the radiative impact of clouds and also to determine the distribution of condensed water or ice in the atmosphere. For optically thick clouds, only combined lidar and radar measurements provide their "real" geometrical thickness. The second subsection studies in more detail the height of the lidar maximum backscatter signal within the cloud and the radiative cloud height determined by AIRS, in dependence of cloud emissivity and cloud apparent thickness. The latter should be approximately one photon penetration depth into the cloud (e.g. Sherwood et al., 2004), and several case studies (Heymsfield et al., 1991; Sherwood et al., 2004) have shown that even for deep convective clouds with large optical depth this radiative height lies 1 to $2 \mathrm{~km}$ below the cloud top.

\subsection{Position of maximum backscatter, geometrical and "apparent" thickness}

Figure 9 presents normalized frequency distributions of $z_{\text {top }}-z_{\text {mbsc }}($ left panel $)$ and $\left(z_{\text {top }}-z_{\text {mbsc }}\right) /\left(z_{\text {top }}-z_{\text {base }}\right)($ right panel), separately for high opaque clouds, cirrus and thin cirrus in the three latitude bands described in Sect. 2.5. Only AIRS scenes for which all three CALIPSO samples within the AIRS golf ball are declared cloudy and which are homogenous (same AIRS cloud type over nine AIRS footprints of the corresponding AIRS golf ball) are considered. The distributions of $z_{\text {top }}-z_{\text {mbsc }}$ are quite similar for the three cloud types, with a peak of maximum backscatter near the cloud top. Nevertheless, high clouds seem to be slightly more dif-
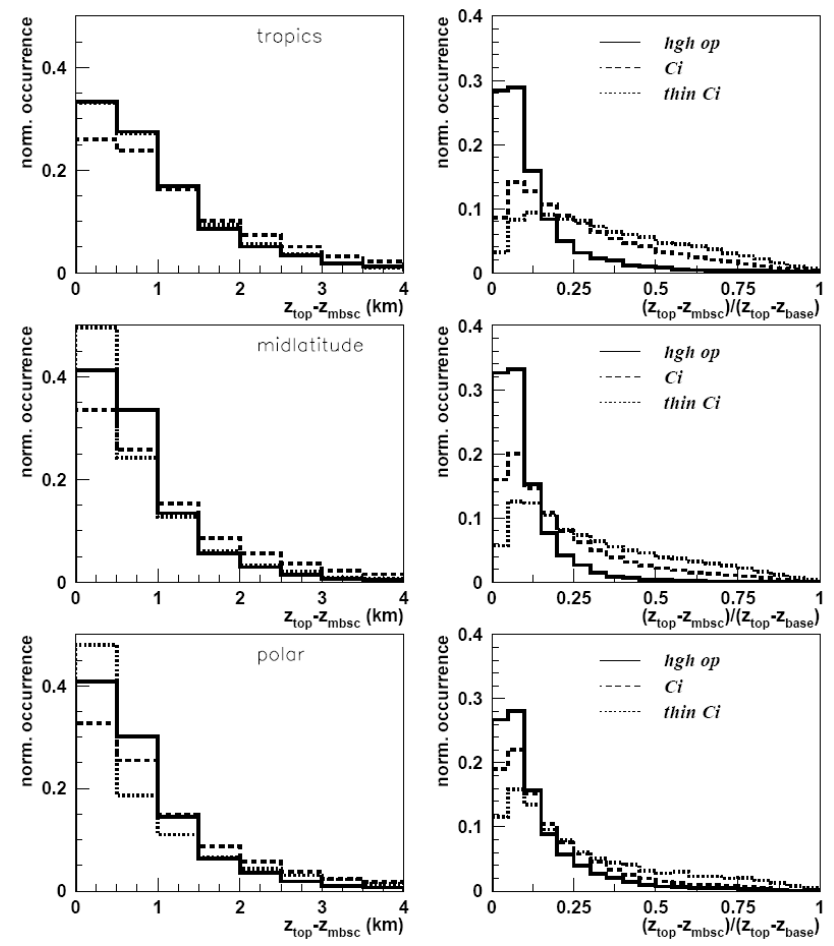

Fig. 9. Normalized frequency distributions of the height of maximum backscatter in relation to the cloud top, separately for high opaque clouds (full line), cirrus (broken line) and thin cirrus (dotted line), as absolute difference $z_{\text {top }}-z_{\text {mbsc }}$ (left panel) and as relative difference $\left(z_{\text {top }}-z_{\text {mbsc }}\right) /\left(z_{\text {top }}-z_{\text {base }}\right)$ (right panel). Distributions are presented for three different latitude bands: $30^{\circ} \mathrm{N}-30^{\circ} \mathrm{S}$ (upper panels), $30^{\circ}-60^{\circ}$ (middle panels) and $60^{\circ}-90^{\circ}$ (lower panels).

fuse in the tropics, where the distributions are broader than in the midlatitudes and in the polar latitudes. The distributions of $\left(z_{\text {top }}-z_{\text {mbsc }}\right) /\left(z_{\text {top }}-z_{\text {base }}\right)$ are quite different for high opaque clouds compared to thinner cirrus: the height of maximum backscatter is near the top, with very few cases of maximum backscatter height in the lower three quarters of the cloud, whereas the distributions of cirrus and thin cirrus are much broader. The difference between high opaque clouds and thinner cirrus can be explained by the much larger vertical extent of high opaque clouds (including Cumulonimbus) compared to the one of cirrus and thin cirrus, as shown in the left panel of Fig. 10. The distributions of vertical extent of high opaque clouds are quite broad (the tropical/subtropical distribution is even nearly flat), with a peak around $10 \mathrm{~km}$ in the midlatitudes and around $8 \mathrm{~km}$ in the polar latitudes. This means that these clouds may extend over the whole troposphere. Note, however, that this type of cloud only covers about $3 \%$ of the globe (Table 4). Cirrus vertical extent peaks around $4 \mathrm{~km}$ in the tropics, $5 \mathrm{~km}$ in the midlatitudes and around $8 \mathrm{~km}$ in the polar latitudes. The distributions of vertical extent of optically thin cirrus peak around $2 \mathrm{~km}$, with a quite broad distribution in the polar latitudes. It is interesting 

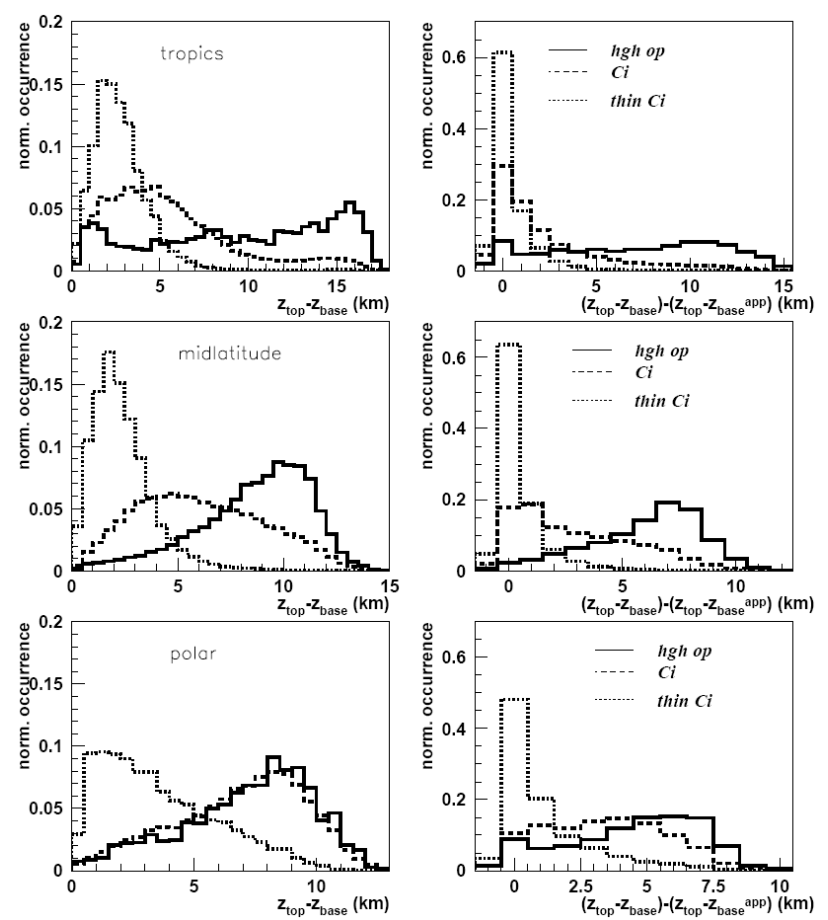

Fig. 10. Normalized frequency distributions of the geometrical cloud thickness (left panel), separately for high opaque clouds (full line), cirrus (broken line) and thin cirrus (dotted line), obtained from Radar-Lidar GEOPROF data, and of the difference between geometrical cloud thickness from Radar-Lidar GEOPROF data and the one obtained from CALIPSO (right panel). Distributions are presented for three different latitude bands: $30^{\circ} \mathrm{N}-30^{\circ} \mathrm{S}$ (upper panels), $30^{\circ}-60^{\circ}$ (middle panels) and $60^{\circ}-90^{\circ}$ (lower panels).

to note that the cirrus distribution resembles more the distribution of thin cirrus in the tropics and shifts towards the one for opaque clouds towards higher latitudes. This is probably linked to the different formation processes (anvil cirrus against storm track cirrus). To highlight the importance of including the CloudSat cloud base, we present in the right panel of Fig. 10 distributions of the difference between cloud vertical extents determined by CALIPSO alone and by the CALIPSO-CloudSat GEOPROF data base. For high opaque clouds the difference may reach more than $10 \mathrm{~km}$ in the tropics, $7 \mathrm{~km}$ in the midlatitudes and $6 \mathrm{~km}$ in the polar latitudes, whereas for optically thin cirrus there is no difference. This result also indicates the quality of the AIRS-LMD cloud type determination.

Since for high opaque clouds the "apparent" geometrical cloud thickness (at which the cloud reaches an optical depth of 5) can be much smaller than the real geometrical cloud thickness, we present in Fig. 11 normalized distributions of this quantity separately for the three latitude bands. Indeed, the distributions lie between 1 and $7 \mathrm{~km}$ with a peak value around $2.5 \mathrm{~km}$ for all three latitude bands. It is the "apparent" geometrical cloud thickness which is more relevant for
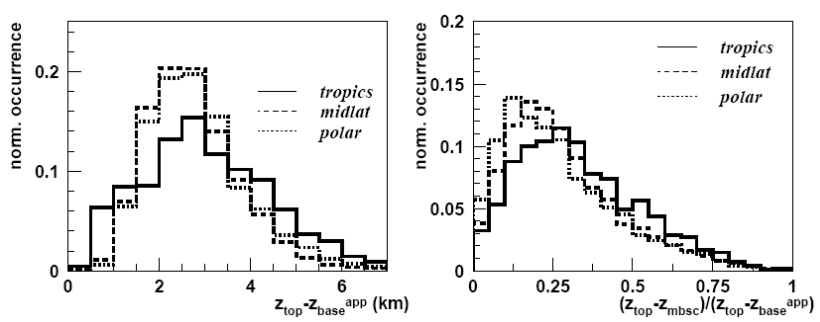

Fig. 11. Normalized frequency distributions of "apparent" cloud geometrical thickness (left) and of the relative height of the maximum backscatter signal compared to the "apparent" cloud geometrical thickness (right) for high opaque clouds, separately for three different latitude bands: $30^{\circ} \mathrm{N}-30^{\circ} \mathrm{S}$ (full line), $30^{\circ}-60^{\circ}$ (broken line) and $60^{\circ}-90^{\circ}$ (dotted line).

radiative effects, and therefore we also explore in Fig. 11 the normalized frequency distributions of the relative height of the maximum backscatter signal compared to the "apparent" cloud geometrical thickness, separately for the three different latitude bands. These distributions show again that in the tropics high opaque clouds are more diffusive, with a peak around $25 \%$ below cloud top in the tropics compared to $20 \%$ below cloud top in the other latitude bands.

\subsection{Relationship between position of maximum backscatter, "radiative" height and "apparent" thickness}

In Sect. 2.4 we have shown that in general the AIRS-LMD "radiative" cloud height compares quite well to the middle of the "apparent" geometrical cloud thickness and also to the height of the maximum backscatter, with a slightly larger dispersion. Two case studies (Holz et al., 2006) have shown that the cloud height retrieved from the Scanning HighResolution Interferometer Sounder (S-HIS) corresponds to the level in the cloud where the Cloud Physics Lidar (CPL) integrated optical depth is approximately 1 . The question in this case would be if $\tau_{\text {cld }}=1$ is reached faster for an opically thick cloud than for an optically thin cloud which would then induce that $z_{\text {cld }}\left(\right.$ AIRS) (further on $z_{\text {AIRS }}$ ) would be closer to the cloud top for optically thick clouds than for optically thin clouds. Therefore we try to explore further the relation between the position of the maximum backscatter signal, the "radiative" height and the "apparent" cloud geometrical thickness. For a better separation between optically thick and thin clouds, we consider high opaque clouds with $\varepsilon_{\text {cld }} \geq 0.95$, cirrus with $0.8>\varepsilon_{\text {cld }}>0.5$ and optically thin cirrus with $0.4>\varepsilon_{\text {cld }}>0.05$, and we demand $\tau_{\text {cld }}=5, \tau_{\text {cld }}>0.5$ and $\tau_{\text {cld }}<1.5$, respectively, to reduce AIRS misidentification due to heterogeneous scenes. For the determination of $z_{\text {top }}-z_{\text {AIRS }}$, we need atmospheric profiles of good quality. These are available only for optically thin cirrus. For the other cloud types, a running mean over a week or a monthly average of good quality profiles is used. 

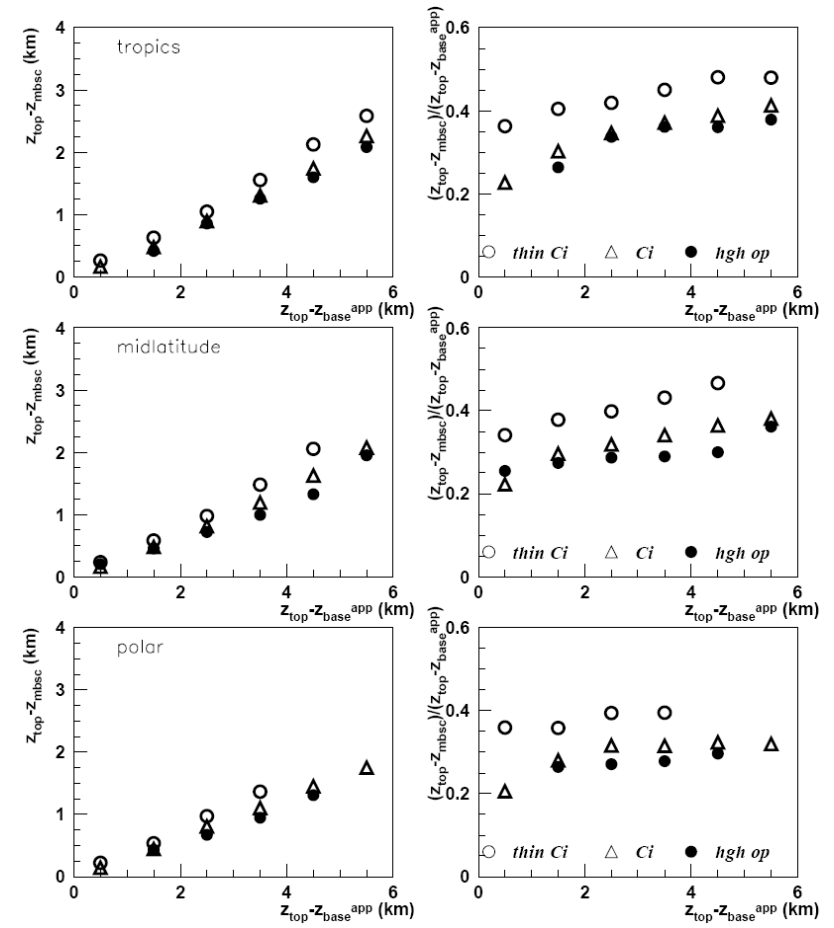

Fig. 12. Average difference between cloud top and height of maximum backscatter (right panels) and average difference relative to "apparent" cloud geometrical thickness (left panels) as a function of "apparent" cloud geometrical thickness, separately for high opaque clouds (full circles), cirrus (open triangles) and thin cirrus (open circles) and for three different latitude bands: $30^{\circ} \mathrm{N}-30^{\circ} \mathrm{S}$ (upper panels), $30^{\circ}-60^{\circ}$ (middle panels) and $60^{\circ}-90^{\circ}$ (lower panels).

Figure 12 presents $z_{\text {top }}-z_{\text {mbsc }}$ (left) and $\left(z_{\text {top }}-\right.$ $\left.z_{\text {mbcs }}\right) /\left(z_{\text {top }}-z_{\text {base }}^{\text {app }}\right)$ (right) as a function of "apparent" geometrical cloud thickness, $z_{\text {top }}-z_{\text {base }}^{\text {app }}$, again separately for the three cloud types and for the three latitude bands. We observe a nearly linear increase of the average depth of the signal of maximum backscatter with increasing "apparent" cloud geometrical thickness, reaching $2.5 \mathrm{~km}$ at an "apparent" geometrical cloud thickness of $6 \mathrm{~km}$. High opaque clouds and cirrus show the same behaviour. There seems to be a slightly stronger increase for thin cirrus. The slope is slightly weaker in the polar latitudes. Considering the relative depth of the signal of maximum backscatter, we observe an increase of only about $10 \%$ over the range of "apparent" cloud thickness. At the same "apparent" cloud thickness the maximum backscatter of optically thin cirrus is about 10\% deeper inside the cloud than for the other cloud types.

Figure 13 presents $z_{\text {top }}-z_{\text {AIRS }}$ (left) and $\left(z_{\text {top }}-\right.$ $\left.z_{\text {AIRS }}\right) /\left(z_{\text {top }}-z_{\text {base }}^{\text {app }}\right)$ (right) as function of $z_{\text {top }}-z_{\text {base }}^{\text {app }}$, for the same cloud types and latitude bands as in Fig. 12. High opaque clouds and cirrus show an increase of $z_{\text {top }}-z_{\text {AIRS }}$ as function of $z_{\text {top }}-z_{\text {base }}^{\text {app }}$, similar to the behaviour of $z_{\text {top }}-$ $z_{\text {mbsc }}$. It is interesting to note that even for high opaque
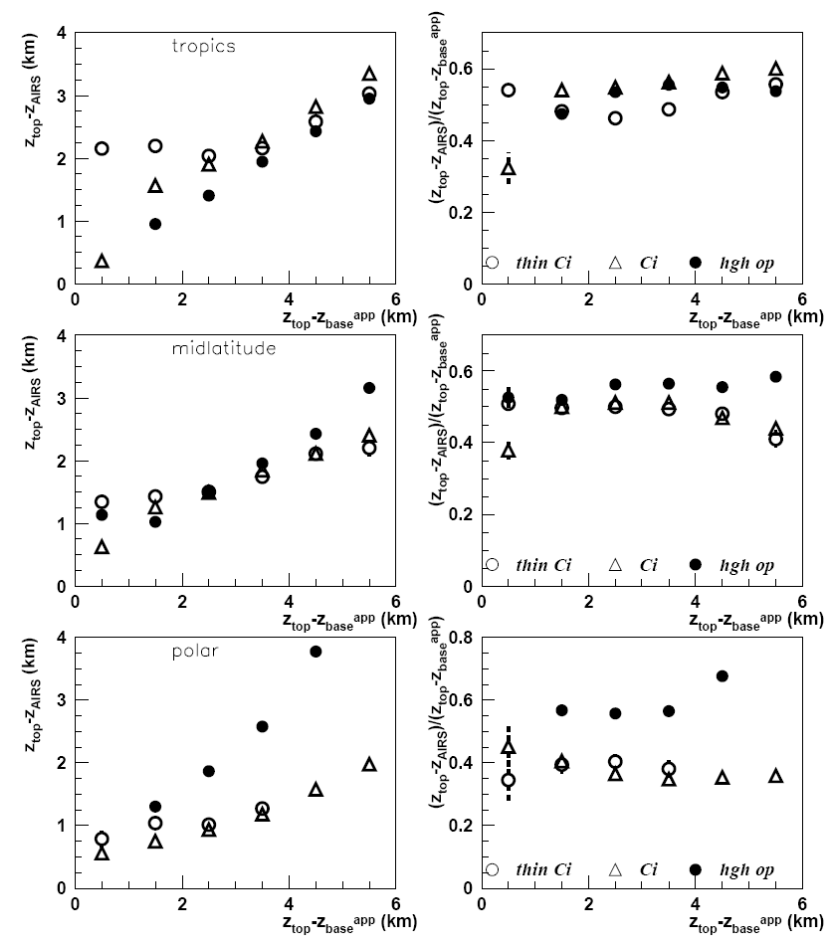

Fig. 13. Average difference between cloud top and "radiative" cloud height (left panels) and average difference relative to "apparent" cloud geometrical thickness (right panels) as a function of "apparent" cloud geometrical thickness, separately for high opaque clouds (full circles), cirrus (open triangles) and thin cirrus (open circles) and for three different latitude bands: $30^{\circ} \mathrm{N}-30^{\circ} \mathrm{S}$ (upper panels), $30^{\circ}-60^{\circ}$ (middle panels) and $60^{\circ}-90^{\circ}$ (lower panels).

clouds the "radiative" cloud height depends on the "apparent" cloud thickness and can be as low as $3 \mathrm{~km}$ beneath the cloud top. Earlier case studies by Heymsfield et al. (1991) and Sherwood et al. (2004) have already drawn attention to this problem. On average, the "radiative" cloud height of high opaque clouds lies between 0.5 and $1.5 \mathrm{~km}$ below the cloud top. In comparison to Fig. 12, "radiative" cloud height seems to be about 10 to $20 \%$ lower than the position of maximum backscatter at the same "apparent" geometrical thickness. In general, the "radiative" cloud height seems to be close to the "apparent middle" of the cloud (or sightly below), independent of "apparent" geometrical cloud thickness. In polar latitudes, the spread of "radiative" height between cirrus and high opaque clouds is larger. This could perhaps be linked to the different vertical structure of the clouds and their different formation process. Further investigations are needed to draw conclusions, because in these regions the atmospheric profiles are more difficult to retrieve and the cloud height over ice has larger uncertainties. 


\subsection{Relationship between distance of cloud top to tropopause and geometrical thickness}

Our collocated data set should also give some information on the height of clouds with respect to the tropopause. We are especially interested in clouds penetrating into the stratosphere. This phenomenon has been observed for deep convection in the tropics (e.g. Zhang, 1993; Gettelman et al., 2002; Hong et al., 2008). The tropics should also show widespread layers of cirrus near the tropopause. Figure 14 presents the difference between the height of the thermal tropopause, given by CALIPSO (from GMAO), and CALIPSO cloud top height as function of real geometrical cloud thickness, obtained from radar-lidar GEOPROF data, separately for high opaque clouds with $\varepsilon_{\text {cld }} \geq 0.95$, cirrus with $0.8>\varepsilon_{\text {cld }}>0.5$ and optically thin cirrus with $0.4>\varepsilon_{\text {cld }}>0.05$ identified by AIRS in the three latitude bands. In the tropics we observe that only the opaque clouds that are the thickest geometrically and (the probably surrounding anvil) cirrus penetrate the stratosphere. These vertically extending clouds likely correspond to larger organized, mesoscale convective systems, which more often lead to penetrating convection than smaller, unorganized convective systems as has been shown by Rossow and Pearl (2007). Opaque clouds with smaller geometrical thickness reach to about $2 \mathrm{~km}$ below the tropopause. In the midlatitudes and polar latitudes, the cloud top height relative to the tropopause differs much less between high opaque clouds and cirrus, and there is a smooth increase with increasing geometrical cloud thickness.

\section{Conclusions}

We have presented properties of a six-year global cloud climatology from the Atmospheric InfraRed Sounder AIRS, using the AIRS LMD cloud retrieval. The retrieval is based on a weighted $\chi^{2}$ method on radiances around the $15 \mu \mathrm{m} \mathrm{CO}_{2}$ absorption band. Auxiliary data are AIRS L2 atmospheric profiles and pre-computed spectral transmissivity profiles from the TIGR data set, as well as spectral surface emissivities from AIRS and MODIS. Cloud amount is essentially determined by testing the spectral coherence of retrieved cloud emissivities. In addition, clouds over land are restricted to a temperature $3 \mathrm{~K}$ less than the surface air temperature. Over snow and ice covered surface, a test on atmospheric temperature inversions takes out probable clear sky.

This "a posteriori" cloud detection leads to an overall coincident agreement with CALIPSO of about $85 \%$ over ocean and of about $75 \%$ over land. Also the zonal averages of cloud amount agree very well with the ones determined by CALIPSO, when excluding subvisible cirrus. Only at higher latitudes in winter, total cloud amount over snow and ice seems to be underestimated, whereas the total cloud amount of the TOVS Path-B climatology, using a multi-spectral cloud detection also based on the simultane-
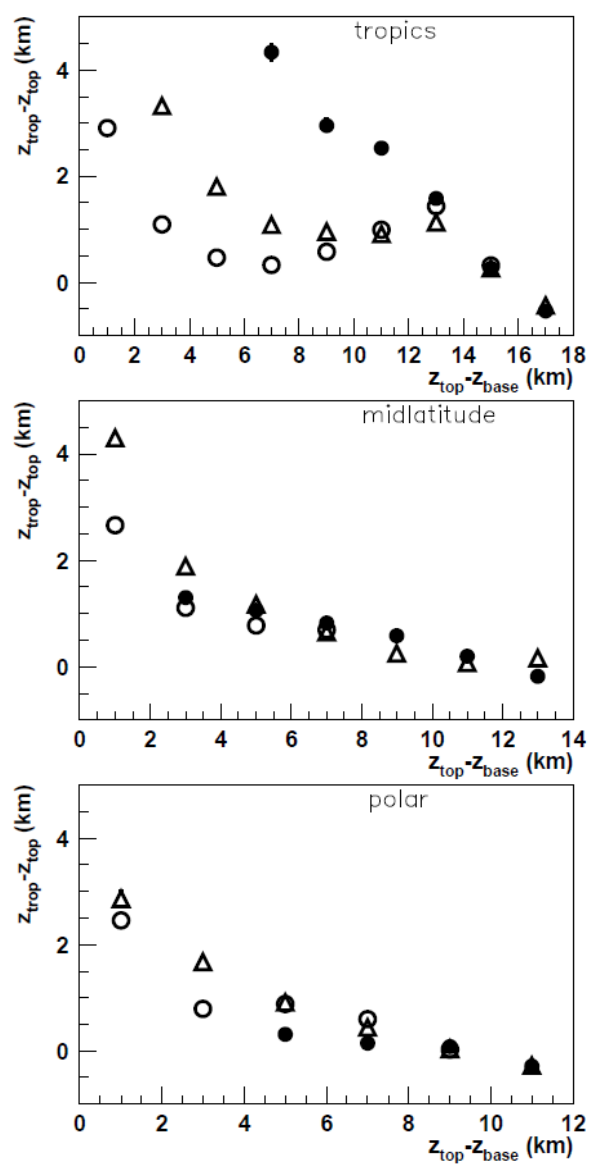

Fig. 14. Average difference between the height of the tropopause and the cloud top as a function of real cloud geometrical thickness, separately for high opaque clouds (full circles), cirrus (open triangles) and thin cirrus (open circles) and for three different latitude bands: $30^{\circ} \mathrm{N}-30^{\circ} \mathrm{S}$ (upper panel), $30^{\circ}-60^{\circ}$ (middle panel) and $60^{\circ}-90^{\circ}$ (lower panel).

ous use of microwave channels, and of the ISCCP climatology, using a $3.7 \mu \mathrm{m}$ channel during night, compare well to the one of CALIPSO.

Global cloud amount has been estimated as about $66 \%$ to $74 \%$, depending on the weighting of not cloudy AIRS footprints by partial cloud cover between 0 and 0.3 . There are about $10 \%$ more clouds over ocean than over land. $42 \%$ of all clouds are high clouds, and about $42 \%$ of all clouds are single layer low-level clouds. When considering also subvisible cirrus, global cloud amount increases to $80 \%$ and high clouds make out $50 \%$ of all clouds. The largest fraction of high clouds is situated in the tropics and the largest fraction of single layer low-level clouds in the Southern hemisphere midlatitudes. Only about $10 \%$ of all clouds in the tropics are single layer midlevel clouds, in agreement with earlier observations by Mace and Benson-Troth (2002). As the fraction of detected cirrus depends on instrument sensitivity, the active lidar is the most sensitive instrument, followed by IR sounders. 
ISCCP underestimates high cloud amount, especially in the tropics where these clouds are most abundant. Thin cirrus overlying low-level clouds are falsely identified as midlevel clouds by ISCCP. When distinguishing high clouds by their IR emissivity, one observes that high opaque clouds only cover a very small fraction of our globe: about 3\%, in agreement with ISCCP (Rossow and Schiffer, 1999).

Cloud height of the AIRS LMD cloud retrieval has been evaluated using the height of the maximum backscatter signal and of the "apparent middle" of the highest cloud layer detected by CALIPSO, excluding subvisible cirrus. All difference distributions (for high and low clouds as well as in the tropics, midlatitudes and polar latitudes) are Gaussian with a strong peak around 0 . This means that the "radiative" height determined by the AIRS-LMD retrieval corresponds well to the height of the maximum backscatter signal and of the "apparent middle" of the cloud. A comparison of the cloud height provided by the AIRS L2 products with CALIPSO exhibits a strong negative bias in the cloud pressure of low clouds, in agreement with a study of Kahn et al. (2008).

We used the unique constellation of the A-Train, with its two active instruments, to explore the "apparent" and the real geometrical cloud thickness, as well as the depth of maximum backscatter, indicating the diffusiveness of clouds. Whereas the real cloud thickness of high opaque clouds may fill the whole troposphere, their "apparent" cloud thickness (at which optical thickness reaches about 5) is on average only $3 \mathrm{~km}$. We also showed that the real geometrical thickness of thin cirrus as identified by AIRS-LMD is identical to the "apparent" cloud thickness with an average of about $2.5 \mathrm{~km}$ in the tropics and midlatitudes.

In general, the depth of the maximum backscatter signal increases nearly linearly with increasing "apparent" cloud thickness. Even for high opaque clouds, the height of maximum backscatter lies on average about 35\%/30\% and 25\% below cloud top relative to "apparent" geometrical thickness, respectively in the tropics, midlatitudes and polar latitudes. This indicates that high clouds in the tropics have slightly more diffusive cloud tops than at higher latitudes. For the same "apparent" cloud thickness optically thin cirrus show a maximum backscatter about $10 \%$ deeper inside the cloud than optically thicker clouds.

The difference between cloud top and "radiative" height also increases with increasing "apparent" cloud thickness for high opaque clouds and cirrus. However, relatively speaking, the "radiative" cloud height seems to be close to the "apparent middle" of the cloud (or sightly below), independent of "apparent" geometrical cloud thickness. It also seems to be slightly lower than the position of maximum backscatter. It is interesting to note that even for high opaque clouds the "radiative" cloud height depends on the "apparent" cloud thickness and can be as low as $3 \mathrm{~km}$ beneath the cloud top.
When relating the distance between the tropopause and the cloud top to the real cloud thickness, we observe in the tropics that only the geometrically thickest opaque clouds and (the probably surrounding anvil) cirrus penetrate the stratosphere. These vertically extending clouds correspond possibly to larger organized, mesoscale convective systems, which lead more often to penetrating convection than smaller, unorganized convective systems as shown by Rossow and Pearl (2007).

This 6-year global cloud climatology participates in the GEWEX cloud assessment (http://climserv.ipsl. polytechnique.fr/gewexca), and in this framework further analyses of average cloud properties as well as their regional, seasonal and interannual variations from all participating climatologies are in progress (Stubenrauch et al., 2009). The AIRS-LMD cloud climatology will be made available at http://ara.lmd.polytechnique.fr.

Acknowledgements. This work has been financially supported by CNRS and by CNES, and in part by the European Community under the contract FP6-516099. The authors thank the members of the AIRS, CALIPSO and CloudSat science teams for their efforts and cooperation in providing the data as well as the engineers and space agencies who control the quality of the data. We also want to thank our other colleagues from the Atmospheric Radiation Analysis (ARA) team at LMD for technical support. Special thanks to Dave Winker for fruitful discussions about analyzing the CALIPSO L2 data and to Gerald Mace and Donald Reinke for help with the Radar Lidar GEOPROF data, as well as to two anonymous reviewers who contributed to a better formulated manuscript.

Edited by: S. Buehler

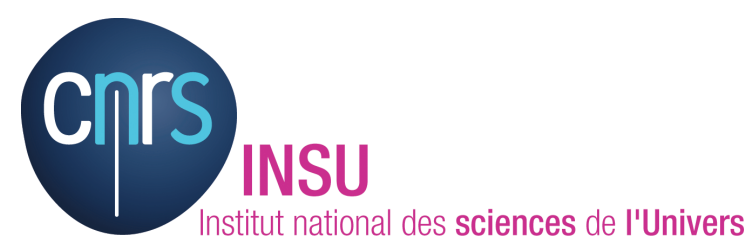

The publication of this article is financed by CNRS-INSU.

\section{References}

Ackerman, S. A., Smith, W. L., Collard, A. D., Ma, X. L., Revercomb, H. E., and Knuteson, R. O.: Cirrus cloud properties derived from high-spectral resolution infrared spectrometry during FIRE II, Part II: Aircraft HIS results, J. Atmos. Sci., 52, 42464263, 1995.

Aumann, H. H., Chahine, M. T., Gautier, C., Goldberg, M. D., et al.: AIRS/AMSU/HSB on the Aqua mission: Design, science objectives, data products, and processing systems, IEEE T. Geosci. Remote, 41, 253-264, 2003.

Chahine, M. T., Pagano, T. S., Aumann, H. H., Atlas, R., and Coauthors: AIRS: Improving weather forecasting and providing new data on greenhouse gases, B. Am. Meteor. Soc., 87, 911-926, 2006. 
Chédin, A., Scott, N. A., Wahiche, C., and Moulinier, P.: The improved initialization inversion method: A high resolution physical method for temperature retrievals from satellites of the TIROS-N series, J. Clim. Appl. Meteor., 24, 128-143, 1985.

Chédin, A., Serrar, S., Scott, N. A., Crevoisier, C., and Armante, R.: First global measurement of midtropospheric $\mathrm{CO}_{2}$ from NOAA polar satellites: Tropical zone, J. Geophys. Res., 108(D18), 4581, doi:101029/2003JD003439, 2003.

Chevallier, F., Cheruy, F., Scott, N. A., and Chédin, A.: A neural network approach for a fast and accurate computation of longwave radiative budget, J. Appl. Meteor., 37, 1385-1397, 1998.

Chung, S. G., Ackerman, S. A., Van Delst, P. F., and Menzel, W. P.: Model Calculations and Interferometer Measurements of IceCloud Charancteristics, J. Appl. Meteor., 39, 634-644, 2000.

Divakarla, M. G., Barnet, C. D., Goldberg, M. D., McMillin, L. M., Maddy, E., Wolf, W., Zhou, L., and Liu, X.: Validation of Atmospheric Infrared Sounder temperature and water vapour retrievals with matched radiosonde measurements and forecasts, J. Geophys. Res., 111(D9), D09S15, doi:10.129/205JD006116, 2006.

Frey, R. A., Ackerman, S. A., Liu, Y., Strabala, K. I., Zhang, H., Key, J. R., and Wang, X.: Cloud Detection with MODIS. Part I: Improvements in the MODIS Cloud Mask for Collection 5, J. Atmos. Ocean. Tech., 25, 1057-1072, 2008.

Gettelman, A., Salby, M. L., and Sassi, F.: Distribution and influence of convection in the tropical tropopause region, J. Geophys. Res., 107(D10), 4080, doi:10.1029/2001JD001048, 2002.

Heymsfield, G. M., Fulton, R., and Spinhirne, J. D.: Aircraft overflight measurements of Midwest severe storms: Implications on geosynchronous satellite interpretations, Mon. Weather Rev., 119, 436-456, 1991.

Holz, R. E., Ackerman, S., Antonelli, P., Nagle, F., Knuteson, R. O., McGill, M., Hlavka, D. L., and Hart, W. D.: An Improvement to the High-Spectral-Resolution $\mathrm{CO}_{2}$-Slicing Cloud-Top Altitude Retrieval, J. Atmos. and Ocean. Tech., 23, 653-670, 2006.

Hong, G., Heygster, G., Notholt, J., and Buehler, S. A.: Interannual to Diurnal Variations in Tropical and Subtropical Deep Convective Clouds and Convective Overshooting from Seven Years of AMSU-B Measurements, J. Climate, 21, 4168-4189, 2008.

Jin, Y. and Rossow, W. B.: Detection of cirrus overlapping low-level clouds. J. Geophys. Res., 102, 1727-1737, 1997.

Kahn, B. H., Eldering, A., Braverman, A. J., Fetzer, E. J., Jiang, J. H., Fishbein, E., and Wu, D. L.: Toward the characterization of upper tropospheric clouds using Atmospheric Infrared Sounder and Microwave Limb Sounder observations, J. Geophys. Res., 112, D05202, doi:10.1029/2006JD007336, 2007.

Kahn, B. H., Chahine, M. T., Stephens, G. L., Mace, G. G., Marchand, R. T., Wang, Z., Barnet, C. D., Eldering, A., Holz, R. E., Kuehn, R. E., and Vane, D. G.: Cloud type comparisons of AIRS, CloudSat, and CALIPSO cloud height and amount, Atmos. Chem. Phys., 8, 1231-1248, doi:10.5194/acp-8-1231-2008, 2008.

Lamquin, N., Stubenrauch, C. J., and Pelon, J.: Upper tropospheric humidity and cirrus thickness : a statistical analysis using one year of collocated AIRS and CALIPSO data, J. Geophys. Res., 113, D00A10, doi:10.1029/2008JD009928, 2008.

Liao, X., Rossow, W. B., and Rind, D.: Comparison between SAGE II and ISCCP high-level clouds: 2. Locating cloud tops, J. Geophys. Res., 100, 1137-1147, 1995.
Liu, Y. and Key, J. R.: Detection and analysis of clear-sky, lowlevel atmospheric temperature inversions with MODIS, J. Atmos. Ocean. Tech., 20, 1727-1737, 2003.

Mace, G. G. and Benson-Troth, S.: Cloud overlap characteristics derived from long-term cloud radar data, J. Climate, 15, 24052515, 2002.

Mace, G. G., Marchand, R., Zhang, Q., and Stephens, G.: Global hydrometeor occurrence as observed by Cloudsat: Initial observations from summer 2006, Geophys. Res. Lett., 34, L09808, doi:10.1029/2006GL029017, 2007.

Mace, G. G., Zhang, Q., Vaughan, M., Marchand, R., Stephens, G., Trepte, C., and Winker, D.: A description of hydrometeor layer occurrence statistics derived from the first year of merged Cloudsat and CALIPSO data, J. Geophys. Res., 114, D00A26, doi:10.1029/2007JD009755, 2009.

Marchand, R. T., Mace, G. G., and Ackerman, T. P.: Hydrometeor detection using CloudSat: An Earth orbiting $94 \mathrm{GHz}$ cloud radar, J. Atmos. Ocean. Tech., 25, 519-533, 2008.

Péquignot, E., Chédin, A., and Scott, N. A.: Infrared continental surface emissivity spectra retrieved from AIRS hyperspectral sensor, J. Appl. Meteor. Climatol., 47, 1619-1633, 2008.

Rossow, W. B., Walker, A. W., Beuschel, D., and Roiter, M.: International Satellite Cloud Climatology Project (ISCCP): Description of New Cloud Datasets. WMO/TD-No.737, World Climate Research Programme (icsu and WMO), Geneva, February 1996, 115 pp., 1996.

Rossow, W. B. and Schiffer, R. A.: Advances in understanding clouds from ISCCP, B. Am. Meteor. Soc., 80, 2261-2287, 1999.

Rossow, W. B. and Pearl, C.: 22-Year survey of tropical convection penetrating into the lower stratosphere, Geophys. Res. Lett., 34, L04803, doi:10.1029/2006GL028635, 2007.

Sandu, I., Stevens, B., and Pincus, R.: On the transitions in marine boundary layer cloudiness, Atmos. Chem. Phys., 10, 2377-2391, doi:10.5194/acp-10-2377-2010, 2010.

Sassen, K., Wang, Z., and Liu, D.: Global distribution of cirrus clouds from CloudSat/Cloud-Aerosol Lidar and Infrared Pathfinder Satellite Observations (CALIPSO) measurements, J. Geophys. Res., 113, D00A12, doi:10.1029/2008JD009972, 2008.

Scott, N. A., and Chédin A.: A fast line-by-line method for atmospheric absorption computations: the 4A Automized Atmospheric Absorption Atlas, J. Appl. Meteor., 20, 801-812, 1981.

Scott, N. A., Chédin, A., Armante, R., Francis, J., Stubenrauch, C. J., Chaboureau, J.-P., Chevallier, F., Claud, C., and Chéruy, F.: Characteristics of of the TO,VS Pathfinder Path-B Data set, B. Am. Meteor. Soc., 80, 2679-2701, 1999.

Seemann, S. W., Borbas, E. E., Knuteson, R. O., Stephenson, G. R., and Huang, H. L.: Development of a Global Infrared Land Surface Emissivity Database for Application to Clear Sky Sounding Retrievals from Multispectral Satellite Radiance Measurements. J. Appl. Meteor. Climatol., 47, 108-123, doi:10.1175/2007JAMC1590.1, 2008.

Smith, W. L., Ackerman, S. A., Revercomb, H., Huang, H., DeSlover, D. H., Feltz, W., Gumley, L., and Collard, A. D.: Infrared spectral absorption of nearly invisible cirrus clouds, Geophys. Res. Lett., 25, 1137-1140, 1998.

Stephens, G. L., Vane, D. G., Boain, R. J., Mace, G. G., Sassen, K., et al.: The CloudSat mission and the A-train, B. Am. Meteor. Soc., 83, 1771-1790, 2002. 
Stubenrauch, C. J., Chédin, A., Armante, R., and Scott, N. A.: Clouds as Seen by Satellite Sounders (3I) and Imagers (ISCCP): II) A New Approach for Cloud Parameter Determination in the 3I Algorithms, J. Climate, 12, 2214-2223, 1999a.

Stubenrauch, C. J., Rossow, W. B., Scott, N. A., and Chédin, A.: Clouds as seen by Infrared Sounders (3I) and Imagers (ISCCP): Part III) Spatial Heterogeneity and Radiative Effects, J. Climate, 12, 3419-3442, 1999b.

Stubenrauch C. J., Chédin, A., Rädel, G., Scott, N. A., and Serrar, S.: Cloud properties and their seasonal and diurnal variability from TOVS Path-B, J. Climate, 19, 5531-5553, 2006.

Stubenrauch, C. J., Cros, S., Lamquin, N., Armante, R., Chédin, A., Crevoisier, C., and Scott, N. A.: Cloud properties from AIRS and evaluation with CALIPSO, J. Geophys. Res., 113, D00A10, doi:10.1029/2008JD009928, 2008.

Stubenrauch, C. J., Kinne, S., and GEWEX Cloud Assessment Team: Evaluation of Global Cloud Data Products, GEWEX news article, 19(1), 6-7, 2009.

Susskind, J., Barnet, C., and Blaisdell, J.: Retrieval of atmospheric and surface parameters from AIRS/AMSU/HSB data in the presence of clouds, IEEE T. Geosci. Remote., 41, 390-409, 2003.

Susskind, J., Barnet, C., Blaisdell, J., Iredell, L., Keita, F., Kouvaris, L., Molnar, G., and Chahine, M.: Accuracy of geophysical parameters derived from AIRS/AMSU as a function of fractional cloud cover, J. Geophys. Res., 111, D09S17, doi:10.1029/2005JD006272, 2006.

Tobin, D. C., Revercomb, H. E., Knuteson, R. O., Lesht, B. M., Strow, L. L., Hannon, S. E., Feltz, W. F., Moy, L. A., Fetzer, E. J., and Cress, T. S.: Atmospheric Radiation Measurement site atmospheric state best estimates for Atmmospheric Infrared Sounder temperature and water vapour retrieval validation, J. Geophys. Res., 111(D9), D09S14, doi:10.1029/2005JD006103, 2006.

Vaughan, M., Young, S., Winker, D., Powell, K., Omar, A., Liu, Z., Hu, Y., and Hostetler, C.: Fully automated analysis of spacebased lidar data: An overview of the CALIPSO retrieval algorithms and data products, Proc. SPIE Int. Soc. Opt. Eng., 5575, 16-30, 2004.
Wang, J., Rossow, W. B., and Zhang, Y.: Cloud Vertical Structure and its Variations from a 20-Yr Global Rawinsonde Dataset, J. Climate, 13, 3041-3056, 2000.

Wang, P.-H., Minnis, P., McCormick, M. P., Kent, G. S., Skeens, K. M.: A 6-Year Climatology of Cloud Occurrence Frequency from Stratospheric Aerosol and Gas Experiment II Observations (1985-1990), J. Geophys. Res., 101, 29407-29429, 1996.

Wielicki, B. A. and L. Parker: On the Determination of Cloud Cover From Satellite Sensors: The Effect of Sensor Spatial Resolution, J. Geophys. Res., 97(D12), 12799-12823, 1992.

Winker, D. M. and Trepte, C. R.: Laminar cirrus observed near the tropical tropopause by LITE, Geophys. Res. Lett., 25, 33513354, 1998.

Winker, D. M., Hunt, W. H., and McGill, M. J.: Initial performance assessment of CALIOP, Geophys. Res. Lett., 34, L19803, doi:10.1029/2007GL030135, 2007.

Winker, D., Getzewitch, B., and Vaughan, M.: Evaluation and Applications of Cloud Climatologies from CALIOP, Proc. Int. Laser Radar Conference (ILRC), 2008.

Winker, D. M., Vaughan, M. A., Omar, A., Hu, Y., and Powell, K. A.: Overview of the CALIPSO mission and CALIOP data processing algorithms, J. Atmos. Ocean. Tech., 26, 2310-2323, 2009.

Wylie, D. P., Menzel, W. P., and Strabala, K. I.: Four years of global cirrus cloud statistics using HIRS, J. Climate, 7, 19721986, 1994.

Wylie, D. P. and Menzel, W. P. : Eight years of cloud statistics using HIRS, J. Climate, 12, 170-184, 1999.

Zhang, C.: On the annual cycle in highest, coldest clouds in the tropics, J. Climate, 6, 1987-1990, 1993. 